\title{
Numerical experiments on breaking waves on contrasting beaches using a two-phase flow approach
}

\author{
R. Bakhtyar ${ }^{* 1}$, D.A. Barry ${ }^{1}$, C.E. Kees ${ }^{2}$
}

${ }^{1}$ Laboratoire de technologie écologique, Institut d'ingénierie de l'environnement, Faculté de l'environnement naturel, architectural et construit (ENAC), Station 2, Ecole polytechnique fédérale de Lausanne (EPFL), 1015 Lausanne, Switzerland. Tel: +41 (21) 693-8087, +41 (21) 693-5576, Fax: +41 (21) 693-8035, E-mails: roham.bakhtyar@epfl.ch, andrew.barry@epfl.ch

2 Coastal and Hydraulics Laboratory, US Army Engineer Research and Development Center, 3909 Halls Ferry Road, Vicksburg, Mississippi 39180-6133, USA. Tel: +1 (601) 405-3609, Fax: +1 (601) 634-4208, E-mail: chris.kees@us.army.mil

Revision submitted to Advances in Water Resources (Special Issue: THESIS), 26 March 2012

\footnotetext{
* Author to whom all correspondence should be addressed
} 


\begin{abstract}
A mechanistic understanding of beach environments needs to account for interactions of oceanic forcing and beach materials, in particular the role of waves on the evolution of the beach profile. A fully coupled two-phase flow model was used to simulate nearshore fluid-sediment turbulent flow in the cross-shore direction. It includes the ReynoldsAveraged Navier-Stokes equations and turbulent stress closures for each phase, and accounts for inter-granular stresses. The model has previously been validated using laboratory-scale data, so the results are likely more reliable for that scale. It was used to simulate wave breaking and the ensuing hydrodynamics and sediment transport processes in the surf/swash zones.
\end{abstract} Numerical experiments were conducted to investigate the effects of varying beach and wave characteristics (e.g., beach slope, sediment grain size, wave periods and heights) on the foreshore profile changes. Spilling and plunging breakers occur on dissipative and intermediate beaches, respectively. The impact of these wave/beach types on nearshore zone hydrodynamics and beach morphology was determined. The numerical results showed that turbulent kinetic energy, sediment concentrations and transport rate are greater on intermediate than on dissipative beaches. The results confirmed that wave energy, beach grain size and bed slope are main factors for sediment transport and beach morphodynamics. The location of the maximum sediment transport is near the breaking point for both beach types. Coarse- and fine-sand beaches differ significantly in their erosive characteristics (e.g., foreshore profile evolutions are erosive and accretionary on the fine and coarse sand beaches, respectively). In addition, a new parameter (based on main driving factors) is proposed that can characterize the sediment transport in the surf and swash zones. The results are consistent with existing physical observations, suggesting that the two-phase flow model is suitable for the simulation of hyperconcentrated mixed water-sediment flows in the nearshore. The model thus has potential as a useful tool for investigating interactions between nearshore hydrodynamics and beach morphology. 
Keywords: Beach morphology; nearshore hydrodynamics; sediment transport; spilling breakers, plunging breakers; turbulent energy; multi-phase flow; RANS; VOF; TKE; $k-\varepsilon$ closure; free surface; surf zone; swash zone; dissipative beach; intermediate beach

$\begin{array}{ll}\text { Abbreviations } & \\ \text { NS } & \text { Navier-Stokes } \\ \text { RANS } & \text { Reynolds-Averaged Navier-Stokes } \\ \text { SWL } & \text { Still Water Level } \\ \text { TKE } & \text { Turbulent Kinetic Energy } \\ \text { VOF } & \text { Volume-Of-Fluid }\end{array}$

\section{Nomenclature}

Variable

$C_{1 \varepsilon}, C_{2 \varepsilon}, C_{3 \varepsilon}$

$C_{D}, C_{L}$

$d$

$D_{50}$

$E_{f}$

$E_{w}$

$F$

$F_{s}$
Description

Dimensions

empirical constants

drag and lift coefficients, respectively

still water depth

$\mathrm{L}$

$50^{\text {th }}$ percentile of the sediment diameter distribution

$\mathrm{L}$

wave energy flux

$\mathrm{MT}^{-1}$

wave energy

$\mathrm{MT}^{-2}$

fluid volume

$\mathrm{L}^{3} \mathrm{~L}^{-3}$

influence of the sediment phase on the turbulence
$\mathrm{LT}^{-2}$ 
$g$

$h$

$h_{\text {max }}$

$H$

$H_{0}$

$\mathbf{k}$

$k$

$k_{\max }$

$L_{0}$

$L$

M

$P$

$t$

$T$

$\mathbf{T}_{s}, \mathbf{T}_{f}$

$\mathbf{V}_{f}, \mathbf{V}_{s}$

$x, z$ magnitude of gravitational acceleration

$\mathrm{LT}^{-2}$

water depth

$\mathrm{L}$

maximum water depth

$\mathrm{L}$

wave height

$\mathrm{L}$

wave height in deep water

$\mathrm{L}$

unit vector in the vertical direction

turbulent kinetic energy

$\mathrm{L}^{2} \mathrm{~T}^{-2}$

maximum turbulent kinetic energy

$\mathrm{L}^{2} \mathrm{~T}^{-2}$

length of incident waves in deep water

$\mathrm{L}$

model domain length

$\mathrm{L}$

hydrodynamic inter-phase forces (drag and lift forces) $\quad \mathrm{ML}^{-2} \mathrm{~T}^{-2}$

pressure

$\mathrm{ML}^{-1} \mathrm{~T}^{-2}$

time

$\mathrm{T}$

wave period

$\mathrm{T}$

$\mathrm{ML}^{-1} \mathrm{~T}^{-2}$

sediment and fluid phase stress tensors, respectively

$\mathrm{LT}^{-1}$

fluid and sediment velocity vectors, respectively

horizontal and vertical directions 
Greek and symbols

$\begin{array}{llc}\tan (\theta) & \text { bed slope } & - \\ \omega & \text { angular frequency } & \mathrm{T}^{-1} \\ \varphi_{f}, \varphi_{s} & \text { volume fraction of fluid and sediment, respectively } & \mathrm{L}^{3} \mathrm{~L}^{-3} \\ \varphi_{s m} & \text { maximum static sediment concentration } & \mathrm{L}^{3} \mathrm{~L}^{-3} \\ v & \text { kinematic viscosity } & \mathrm{L}^{2} \mathrm{~T}^{-1} \\ v_{\mathrm{t}} & \text { eddy viscosity } & \mathrm{L}^{2} \mathrm{~T}^{-1} \\ \varepsilon & \text { turbulence dissipation rate } & \mathrm{L}^{2} \mathrm{~T}^{-3} \\ \Delta t & \text { time step } & \mathrm{T}^{2}\end{array}$

$\rho_{f}, \rho_{s} \quad$ fluid and sediment densities, respectively $\quad \mathrm{ML}^{-3}$

$\xi, \varsigma \quad$ Surf similarity and surf scaling parameters, respectively -

$\begin{array}{llc}\sigma_{k}, \sigma_{\varepsilon} & \text { empirical constants } & - \\ \gamma & \text { internal friction angle of sediment } & - \\ D() / D t & \text { material derivative } & \mathrm{T}^{-1} \\ \nabla \equiv(\partial / \partial x, \partial / \partial z) & \text { gradient vector } & \mathrm{L}^{-1}\end{array}$

\section{Introduction}

Nearshore zones are highly dynamic systems that are characterised by marked fluctuations in salinity, local sediment budget, and foreshore profile changes [1,2]. Surf and 
swash zones with an economic or social interest are generally subject to human intervention, leading to changes in the system ecology [3]. Therefore, the nearshore area needs to be managed efficiently. Assessing the impact of oceanic forcing on sediment transport is essential for understanding the environment in all coastal zones [4].

The quantification of nearshore hydro- and morphodynamics is a prerequisite for coastal engineering design. Wave shoaling/breaking and its effects on sediment transport in the nearshore zone are fundamental for modelling beach morphology [1]. In the design and maintenance of marine structures, for example, coastal engineers need to estimate beach erosion/accretion due to wave motion. Due to the practical and theoretical significance of morphodynamics, combined fluid and sediment transport models of the surf and swash zones have generated considerable interest [2]. In particular, attention has been paid to nearshore motion, since sedimentation controls beach evolution.

Despite its importance, an accurate and complete description of the interactions between sea-level oscillations and sediments in the complex coastal zones (surf and swash zones) is still partially unknown [1,5-7]. While recent studies tried to determine the processes active in this region, nearshore sediment transport remains a weakly understood area that is mainly untreated in existing studies [8,9]. The complex nature of hydrodynamic and sediment transport processes that occur in the nearshore zone, such as wave breaking and associated turbulence and mixed sediment-fluid flow, requires an accurate description of the flow characteristics [10]. In order to predict the evolution of beach morphology with reasonable accuracy and to understand the key processes governing the transport of sediments, comprehensive investigations are needed to study the interactions between breaking waves and swash motions and sediments. 
Nearshore zone hydrodynamics depends on wave characteristics and bed slope [11]. There is considerable variation in the dynamics of flows due to spilling and plunging breakers, as well as the major differences in beach profiles between intermediate and dissipative beaches [12]. Aagaard and Hughes [8] postulated that generally two types of swash regime exist; (i) on steep beaches and (ii) on gentle beaches. On steep beaches, plunging breakers occur and the beach type is intermediate, while on the gentle beaches the breaker and beach type are spilling and dissipative, respectively $[11,13]$. Other parameters that determine the beach type are sediment grain size and wave energy, the latter being proportional to wave characteristics $[1,2]$.

Empirical formulas for sediment transport on beaches, although useful, are limited due to the inherent process interactions and complexity [14]. Similarly, the shallow water equations and Boussinesq-based models that are commonly used in coastal applications are not appropriate for simulating detailed nearshore sediment transport and hydrodynamics [2]. Surf and swash motions vary markedly in both the cross-shore and vertical directions. As these models assume a hydrostatic pressure distribution (zero vertical velocity), they cannot provide realistic details of combined sediment/water flows. Additionally, since the intensity of the turbulence and sediment concentrations are both high, motions of the fluid and sediment phases are tightly coupled [13]. When sediment concentration and bed shear stress magnitude are relatively high (as in the inner surf and swash zones), the inter-granular stress becomes as significant as the fluid-sediment interactions. Existing single-phase flow models cannot simulate inter-granular stresses and average behaviour of particles, and therefore are not able to capture beach morphology accurately. More sophisticated numerical models are required to reproduce in more detail the physics of nearshore motion and interactions between fluid and sediment, and particle and particle.

Recently, two-phase flow models have been recognized as potentially valuable tools for modelling complex coastal engineering and open channel problems. There are basically two 
approaches for two-phase flow modelling: (i) the Lagrangian approach, which follow sample particles and (ii) the Eulerian approach, in which the particles are treated as a continuum [15]. Two-phase flow models that treat separately the sediment and fluid phases provide a sound basis for simulating interactions between phases. Several sediment-laden, two-phase flow models have been reported for simulations of open channel flows [16-22] and sediment transport in estuaries [23]. Such models were used to investigate effects of oscillatory flows on sediment transport in coastal areas [24-26]. Asano [27] presented a two-phase flow model based on the principles of the Kobayashi and Seo model [28] in which the vertical velocity of particles was approximated by empirical relations. Dong and Zhang [29] presented a two-phase flow (with eddy viscosity) model, capable of simulating the fluid and particle motions in oscillatory sheet flows. Liu and Sato [30,31] simulated the sediment transport rate under combined wave/current conditions and under various asymmetric sheet flows. Hsu et al. [25] and Hsu and Hanes [26] developed a fully coupled two-phase flow model to model fluidsediment oscillatory sheet flow and bed profile changes. Additional description and discussion of the two-phase flow modelling approaches that have been used to simulate beach morphology in the coastal area were summarized by Bakhtyar et al. [13,15].

Bakhtyar et al. [13,15,32] developed a two-dimensional (cross-shore), two-phase flow model for simulating nearshore hydrodynamics and morphology on an impermeable beach taking into account fluid-sediment interactions. They used the model to investigate effects of wave motion and wave breaking on foreshore evolution. Nearshore hydrodynamics were simulated using the Navier-Stokes (NS) equations for both fluid and sediment phases in conjunction with a $k$ - $\varepsilon$ turbulence closure model and the Volume-Of-Fluid (VOF) technique for tracking the free surface. Waves were generated by internal source functions inside the computational domain, although infiltration-exfiltration across the beach face was not considered. 
The aim of this work is to use the model of Bakhtyar et al. [13] to evaluate the importance of wave energy (including wave characteristics), sediment grain size, and type of beach (intermediate or dissipative) on foreshore hydrodynamics and profile changes at the laboratory scale, and to consider the results in the light of existing understanding of coupled nearshore sediment and hydrodynamic interactions. The model has not been validated against experimental data since no suitable data sets are accessible currently. On the other hand, the predictive capabilities of the model have been tested in other circumstances: The two-phase flow model used to represent wave-induced sheet flow in the surf zone was validated by Bakhtyar et al. $[15,32]$ using a detailed set of experimental data collected at the laboratory scale. The model results for nearshore hydrodynamics and sediment transport under wavebreaking were consistent with existing understanding of the wave-induced beach morphology in the nearshore zone [13]. Good agreement was found considering different conditions, in particular beach morphology. Thus, the model used in this study is, at least, partially validated and tested at the laboratory scale. Below, hydrodynamics and beach profile evolution due to different wave conditions, grain size and beach type with different configurations in the nearshore zone were investigated numerically.

\section{Numerical Model}

The Euler-Euler sediment-fluid two-phase flow model was used to simulate sediment transport and hydrodynamic processes under wave motion in the nearshore area. The equations for both phases have the same form and were solved identically. The flow and sediment fields were computed using the Reynolds-Averaged Navier-Stokes (RANS) equations (i.e., timeaveraged continuity and momentum equations) for the fluid and sediment phases in conjunction with VOF and the modified $k$ - $\varepsilon$ turbulence closure model. 
The sediment concentrations are significant, and so the turbulence closure model was modified to account for the extra source of production and dissipation of fluid turbulence [33]. The coupling and interactions between the phases were modelled via momentum transfer. Drag and lift interaction forces were considered, while inter-granular stresses were simulated based on Bagnold's theory $[29,34]$. In the VOF technique, the volume fraction of the computational cell occupied by the fluid determines the free surface [13]. In summary, the key governing equations are:

$\frac{\partial \varphi_{f}}{\partial t}+\nabla \cdot\left(\varphi_{f} \mathbf{V}_{f}\right)=0$

$\frac{\partial \varphi_{s}}{\partial t}+\nabla \cdot\left(\varphi_{s} \mathbf{V}_{s}\right)=0$

$\rho_{f} \frac{D_{c} \varphi_{f} \mathbf{V}_{f}}{D t}=-\nabla P \varphi_{f}+\varphi_{f} \rho_{f} \mathbf{g}+\nabla \varphi_{f} \cdot \mathbf{T}_{f}-\mathbf{M}$

$\rho_{s} \frac{D_{s} \varphi_{s} \mathbf{V}_{s}}{D t}=-\nabla P \varphi_{s}+\varphi_{s} \rho_{s} \mathbf{g}+\nabla \varphi_{s} \cdot \mathbf{T}_{s}+\mathbf{M}$

$\frac{D k}{D t}=\nabla \cdot\left(v+\frac{v_{t}}{\sigma_{k}}\right) \nabla k+P_{r}+\frac{\rho_{s}-\rho_{f}}{\rho_{f}} v_{t} \mathbf{g} \nabla \varphi_{f} \cdot \mathbf{k}-\varepsilon-v_{t} F_{s} \nabla \varphi_{f} \cdot \mathbf{k}$,

$$
\frac{D \varepsilon}{D t}=\nabla \cdot\left(v+\frac{v_{t}}{\sigma_{\varepsilon}}\right) \nabla \varepsilon+\frac{\varepsilon}{k}\left(C_{1 \varepsilon} P_{r}+\frac{\rho_{s}-\rho_{f}}{\rho_{f}} v_{t} \mathbf{g} C_{2 \varepsilon} \nabla \varphi_{f} \cdot \mathbf{k}-C_{3 \varepsilon} \varepsilon-v_{t} F_{s} \nabla \varphi_{f} \cdot \mathbf{k}\right)
$$

$$
\frac{\partial F}{\partial t}+\mathbf{V}_{f} \cdot \nabla F=0
$$

$$
\mathbf{M}=\frac{3 \varphi_{s} \rho_{f}}{4 D_{50}} C_{D}\left(\mathbf{V}_{f}-\mathbf{V}_{s}\right)\left|\mathbf{V}_{f}-\mathbf{V}_{s}\right|+\frac{3 \varphi_{s} \rho_{f}}{4 D_{50}} C_{L}\left|\mathbf{V}_{f}-\mathbf{V}_{s}\right| \nabla\left(\mathbf{V}_{f}-\mathbf{V}_{s}\right) \cdot \mathbf{k},
$$


$C_{D}=\left(\frac{24 \mathrm{v}}{D_{50}\left|\mathbf{V}_{f}-\mathbf{V}_{s}\right|}+2\right) \varphi_{f}^{-9 / 2}$ and $C_{L}=\frac{4}{3}$

$F_{s}=\frac{\varphi_{s}}{\varphi_{f}} \frac{3 C_{D}}{4 D_{50}}\left|\mathbf{V}_{f}-\mathbf{V}_{s}\right|^{2}$

$T_{s x z}=\frac{1.2 v \rho_{f}}{\left[\left(\varphi_{s m} / \varphi_{s}\right)^{\frac{1}{3}}-1\right]^{2}} \frac{\partial V_{s x}}{\partial z}$,

$T_{s z z}=\frac{T_{s x z}}{\tan \gamma}$

where $\varphi_{f}$ and $\varphi_{s}$ are the volume fraction of fluid and sediment, respectively $\left(\varphi_{f}+\varphi_{s}=1\right)$;

$\mathbf{V}_{f} \equiv\left(V_{f x}, V_{f z}\right)$ and $\mathbf{V}_{s} \equiv\left(V_{s x}, V_{s z}\right)$ are the fluid and sediment velocity vectors, respectively; $\rho_{f}$ and $\rho_{s}$ are the fluid and sediment densities, respectively; $F$ is the fluid volume per numerical cell volume; $\varphi_{s m}$ is the maximum static sediment concentration; $\mathbf{M}$ is the hydrodynamic interphase force that includes drag and lift forces; $D_{c} / D t$ and $D_{d} / D t$ show material derivatives following the fluid phase velocity and the sediment phase velocity, respectively; $P$ is the pressure; $\mathbf{T}_{s}$ and $\mathbf{T}_{f}$ are, respectively, the sediment phase stress tensor and fluid-phase stress tensor accounting for inter-granular stress, Reynolds stresses and fluid viscous stress; $\mathbf{g}$ is the gravitational acceleration vector; $\mathbf{k}$ is the unit vector in the vertical direction; $\gamma$ is the internal friction angle of sediment; $C_{D}$ and $C_{L}$ are the drag and lift coefficients, respectively; $v$ is the kinematic viscosity; $v_{t}$ is the eddy viscosity; $k$ and $\varepsilon$ are the turbulent kinetic energy (TKE) and turbulent dissipation rate, respectively; $F_{s}$ represents the influence of the sediment phase on the turbulence; and $C_{1 \varepsilon}=1.44, C_{2 \varepsilon}=1.92, C_{3 \varepsilon}=1.2, \sigma_{k}=1, \sigma_{\varepsilon}=1.3$ are the empirical constants. All of the variables are time averaged. 
The two-dimensional (cross-shore) equations were discretized using finite differences in a staggered coordinate system. Stability was controlled mainly by the value of the local Courant number that ensured satisfactory accuracy and stability. The generating-absorbing boundary condition was applied at the entering boundaries for generation of waves. The rough wall boundary condition was implemented on the bed. The boundary conditions for $k$ and $\varepsilon$ at the bottom were specified in a fully turbulent boundary layer taking account of the influence of the existence of the sediment particles. The sediment concentration at the bottom was taken as the maximum concentration, while at the top boundary a zero-flux sediment concentration condition was applied. Bottom shear stress was defined in the turbulent boundary layer via Log-law formula. This numerical model was applied successfully previously, where it was used to simulate sediment transport and bed profile changes in coastal areas $[13,15,32]$. A detailed description of the modelling procedure, boundary conditions, momentum transfer and numerical scheme is given by Bakhtyar et al. [13].

The $k$ - $\varepsilon$ turbulence closure model is known to be very practical, computationally tractable and capable of giving reasonable results in nearshore zone. Yet, this model is based on crude approximations and suffers from known drawbacks, notably in recirculating flows. Although there are some limitations in the $k-\varepsilon$ two-phase flow, a $k-\varepsilon$ two-phase flow model provides a powerful means to describe the sediment transport and hydrodynamics where high sediment concentrations occur, as in nearshore conditions. The model can describe and simulate reasonably the differences in the dynamics of turbulence between spilling and plunging breakers, as well as the significant measured difference between the surf and swash zone turbulence $[12,35]$. It is important to note that most models based on a two-equation $k-\varepsilon$ turbulence model make use of nearly the same values for the empirical constants [33]. This explains in part why this kind of turbulence model is frequently used, and so its application to the surf and swash zones is possibly a valuable addition to its range of applications. Regarding 
the fact that the present model can describe both the mean velocity and turbulence fields, it is anticipated that it shall remain as a powerful tool in the study of nearshore zone dynamics, not only for transient wave motion but also for the time-averaged mean flow. For example, accurate information on the mean flow field in the nearshore is one of the key factors for simulation of sediment transport $[4,35]$. The $k$ - $\varepsilon$ turbulence closure models were validated using a set of experimental data collected at the laboratory scale [15,32]. The $k$ - $\varepsilon$ model results for nearshore hydrodynamics and sediment transport under wave-breaking were consistent with existing understanding of the wave-induced beach morphology in the nearshore zone [12] and show that present approach is maybe one of the best comprises at present at least for very dense flows for laboratory setups, because it can simulate both sediment and fluid and interactions between the two phases.

\section{Results and Discussion}

The patterns of wave breaking depend on the wave height, wave period and beach slope [35]. Below, nearshore hydrodynamics and beach profile changes with different configurations are investigated numerically. Important quantities derived from the simulations are the sediment transport and bottom level changes. Simulations are performed for different wave heights and periods, as well as bed slope and bed grain size, considered for wave shoaling and breaking in the inner surf and swash zones. The results below represent averages of the solution in time (i.e., phase-averaged over the wave period).

\subsection{Model setup}

Nearshore hydrodynamics, type of beach and breaker types can be characterized via the non-dimensional surf similarity parameter, $\xi$ [36], as follows: 
$\xi=\frac{H \omega^{2}}{|\overrightarrow{\mathrm{g}}| \tan ^{2}(\theta)}$,

where $\tan (\theta)$ is the bed slope, $H$ is the wave height, and $\omega$ is the angular frequency. $\xi<2.5$ indicates reflective beaches, $\xi>20$ indicates dissipative beaches, while $2.5<\xi<20$ shows intermediate beaches [37].

The numerical model simulated a laboratory-scale setup. We used the same model setup as in [13] (the base case of present study is the same as [13]). In Fig. 1, the still water depth was $40 \mathrm{~cm}$ and the model simulates a $0.6 \mathrm{~m} \times 8 \mathrm{~m}$ cross-section of the shoreline. The noncohesive sediment particles have a solid density of $2.65 \times 10^{3} \mathrm{~kg} \mathrm{~m}^{-3}$ and the beach is considered as impermeable. As wave energy, beach grain size and bed slope are main factors for sediment transport and beach morphodynamics; typical laboratory wave heights, wave periods and bed slopes were set to simulate the wave motions on a laboratory beach. A series of numerical simulations were applied taking into account two different scenarios and swash regimes: (i) dissipative beach (spilling breaker) and (ii) intermediate beach (plunging breaker). Three different beach slopes, 1:10,1:15 and 1:20 covering steep, moderate and gentle beaches were used. Three different typical wave heights, 10,15 and $20 \mathrm{~cm}$, and three different wave periods, $2.4 \mathrm{~s}, 3 \mathrm{~s}$ and $3.4 \mathrm{~s}$, were selected to cover spilling and plunging breakers. In addition, four sets of simulations using coarse $\left(D_{50}=0.5 \mathrm{~mm}\right.$ and $\left.0.85 \mathrm{~mm}\right)$ and fine $\left(D_{50}=0.15 \mathrm{~mm}\right.$ and $0.35 \mathrm{~mm}$ ) sand beaches were conducted. The selected incident waves covered both typical dissipative and intermediate beaches under different nearshore conditions. Table 1 summarizes the properties of the 10 cases, where $T$ and $\varsigma$ are, respectively, the wave period and surf scaling parameter $-\varsigma=\tan (\theta)\left(L_{0} / H_{0}\right)^{1 / 2}$ [36]; $L_{0}$ and $H_{0}$ are the length and height of incident waves in deep water, respectively. 
In $\S 3.2$, cross-shore variations of phase-averaged water depth, spatial distribution of TKE, and beach profile changes for different wave energy and wave powers (Cases 1-5, Table 1) are presented. Water depth, TKE and foreshore profile changes for both types of beaches and different bed characteristics (Cases 1,6-10, Table 1) are presented in $§ 3.3$.

\subsection{Effect of wave energy and wave power on nearshore hydro- and morphodynamics}

As wave energy, $E_{w}$, dominates the surf and especially swash motions [5], and is proportional to the wave height squared $\left(E_{w}=f\left(H^{2}\right),[38]\right)$; three different wave heights were selected to cover high and medium energy sea states at the laboratory scale. The cross-shore variation of maximum flow depths in the surf and swash zones and for different wave heights are shown in Fig. 2 (cases 1-3, intermediate beaches). On the intermediate beach, the wave height is larger than for the dissipative beach. Generally, water depth is directly related to wave height; thus, the water depth of the larger wave is higher than that for the smaller wave height. It can be seen that, for larger wave heights (cases 2 and 3), water depths at the shoreline (wave setup) are larger than case 1 . For cases 2 and 3, much of the incident wave remains both at the still water shoreline and within the swash zone. The resulting shoreline movement is characterized by the propagation of individual bores on the beach. For case 1, at SWL and within the swash zone, the water depth is small with only a small fraction of individual swash events remains on the beach face. It can be seen that the uprush depth and maximum runup increase with increasing incident wave energy (wave height).

The turbulence associated with a breaking wave can reach the bed, contributing to sediment suspension. Wave-breaking turbulence is a prevailing process in nearshore sediment transport, playing a more important role than boundary layer shear stress [2], while shear stress is also important especially in the swash zone. In addition and due to different hydrodynamic characteristics of contrasting beaches, it is expected that the effects of plunging and spilling 
breakers on sediment transport and, as a result, the erosion and accretion, is different $[12,35]$. The complex nature of beach morphology and mixed sediment-fluid flow in the nearshore zone requires an accurate description of the TKE. Figure 3 depicts the spatial variation of the TKE (average TKE in the vertical profile at any cross-shore distance) for different wave heights in the nearshore zone. The plot shows that the TKE is noticeably greater for case 3 (beach with largest wave energy). It can be observed that the peak of the TKE shifts upward with increasing wave height. These findings are consistent with existing understanding of the turbulence process in the swash zone (e.g. $[11,13])$. The maximum TKE occurs near the breaking point, after which the TKE decreases towards the shore, as expected [12]. The highest TKE for case 3 is an order of magnitude greater than that for case 1, which shows the importance of wave energy on the TKE and consequently on sediment transport.

Figure 4 displays predicted foreshore profile changes in the surf and swash zones and for different wave heights, with erosion below the SWL and deposition above. A bar is generated for all beaches. These results are consistent with previous findings on sediment transport in the swash zone $[4,13]$. The foreshores profile change and bar size are greater for larger wave heights than for smaller wave heights. For case 3, a large volume of material was moved offshore to form a large bar and caused considerable steepening of the beach profile. This is because, on an intermediate beach, TKE, flow velocity, and wave energy are high during both run-up and rundown [11]. Generally, sediment transport in the surf and swash zones is dependent on the wave energy (wave height squared). Increasing wave height leads to an increase in the wave energy and as a result sediment transport.

The wave energy flux in deep water, $E_{f}$, states that wave power is proportional to the wave period and to the square of the wave height [39]: 
$E_{f}=\frac{\rho g^{2}}{64 \pi} H^{2} T$

The wave period controls the wave energy flux and hence has an effect on beach sediment transport [13]. To examine further the behaviour of the beach hydrodynamics and profile changes, their relative change with the wave period were calculated. Figure 5 gives the crossshore variation of phase-averaged water depths in the surf and swash zones and for different wave periods. The wave height for the longer period is higher than that of shorter period, as is evident in Fig. 5. It can be seen that the wave energy flux ( $H$ and $T)$, plays a significant role in the shoreline water depth for all three cases.

Figure 6 shows the TKE spatial variation for different wave periods. The maximum is in the vicinity of the breaking point. Numerical results show that, in the inner surf zone, the TKE increases towards the shoreline until the wave breaks whereas in the swash zone it decreases towards the maximum wave uprush. After the wave breaks, its energy is dissipated considerably due to turbulence. However, wave breaking increases momentum exchange between the water and sediment phases, inter-granular stresses and thereafter sediment transport in the nearshore zone [13]. Moreover, pre-suspended sediments due to wave breaking are transported into the swash zone by the flow, increasing sediment accretion in the upper part of the beach face [2].

Simulated beach profile changes for different wave periods are shown in Fig. 7 (cases 1, 4 and 5). The simulated beach profile displays formation of berm above the SWL and erosion below it. The greatest erosion occurs close to the wave-breaking point. Wave motion prompted the generation of a bar underneath the SWL. A comparison of Figs. 4 and 7 suggests that the magnitude and gradients of sediment transport are considerably greater in the nearshore for the larger wave heights (cases 2 and 3) than for longer wave periods (cases 4 and 5). The 
magnitude of the accretion predicted over the swash zone and erosion in the surf zone are smaller for cases 4 and 5 than that for cases 2 and 3, and matched by minor morphology changes. The profile change patterns for these cases are similar, although there is slightly more erosion below the SWL and the size of the bar developed is a little larger for longer wave periods. The accretion above the SWL is marginally larger for larger wave periods, but the pattern is otherwise similar.

\subsection{Effect of beach type and characteristics on nearshore hydro- and morphodynamics}

The effects of bed slope are examined next, for three slopes, 1:10, 1:15 and 1:20. These cover intermediate (plunging breaker, cases 1,6) and dissipative beaches (spilling breaker, case 7). Figure 8 shows similar results to Figs. 2 and 5, but on different slopes. The simulations demonstrate that for intermediate beaches, relative to dissipative beaches, the wave height is higher and wave-breaking position is changed, depending on the wave characteristics. A comparison of Figs. 2, 5 and 8 shows that water depth inside the surf and swash zones is a function of wave energy and bed slope. The largest maximum water depth was obtained for case 3 (intermediate beach) and the smallest was obtained for case 7 (mildest slope and dissipative beach).

The spatial variation of the TKE for different bed slopes is shown in Fig. 9. It can be seen that the TKE is largest at the beginning of wave breaking, decreases quickly in the boreestablished area, and then decays progressively in the swash zone. This indicates that the TKE near the wave-breaking point occurs mainly in the surf zone where the wave energy transforms into turbulence rapidly in the surface roller region. Numerical results show that, on the intermediate beach, TKE and mixing are larger than for the dissipative beach. A comparison of the spatial variation of the TKE with different wave and beach conditions (Figs. 3, 6 and 9) shows that the TKE magnitude in the largest wave height case (case 3) is highest and smallest 
for case 7 (gentle beach-dissipative condition), and generally, the TKE magnitude depends on the wave and bed characteristics. As wave energy is proportional to the square of wave height [40,41], an increase in the wave energy and TKE can be induced by increasing wave height and, therefore, wave height is more important than the other wave parameters.

Simulated foreshore profiles for different beach slopes in the nearshore zone are presented in Fig. 10 (cases 1, 6 and 7). The numerical simulations reveal that, for intermediate beaches relative to dissipative beaches, the foreshore profile change and bar size are greater, and beach slope is steeper. As the nearshore hydrodynamics are different in intermediate (i.e., plunging breaker) and dissipative (i.e., spilling breakers) beaches, it is expected that the effects of plunging and spilling breakers on the beach morphology (i.e., erosion and accretion) are dissimilar [12]. Numerical results show that the greatest nearshore sediment transport takes place for case 3 when wave energy is maximal.

The foreshore profile evolution on the fine and coarse sand beaches is shown in Fig. 11 (cases 1 and 8-10). For the present set-up and wave conditions and on the coarse beach (cases 1 and 10), sediment transport is on-shoreward, and a berm is formed above the shoreline. In contrast, on the fine grain beach (cases 8 and 9), sediment transport is off-shoreward and erosion occurs on the upper part of beach face. These results are consistent with the laboratory results of Horn et al. [42] and the numerical results of Bakhtyar et al. [43]. The bar's position on the fine sand beach was the same as the position of maximum erosion on the coarse sand beach (in the vicinity of wave breaking). Therefore, at least for present configuration, sediment transport behaviour is erosive (in the offshore direction) on the fine sand beach, while it is accretionary (in the onshore direction) on the coarse sand beach. These different results for fine and coarse sands are due to fact that, for finer sands, the effective weight influence is predominant causing net offshore transport, while for coarser particles, the boundary layer modification effect is predominant causing net onshore transport [44,45]. In general, the results 
of Fig. 11 reveal that sediment grain size is crucial to foreshore profile prediction. These results are consistent with previous observations and modelling [15,43-45].

\section{Discussion}

Panel a of Fig. 12 gives simulated bed level changes for all cases. In general, the results (for cases 1-7) showed accretion in the upper part of the swash zone, and erosion below the SWL, in the inner surf zone and in the vicinity of wave breaking. But, for case 8 (fine sand beach), as mentioned above, the beach profile change is different, with erosion and accretion above and below the SWL, respectively. The beach profile changes were considerably larger for larger wave heights (cases 2 and 3), resulting from the larger gradients in sediment transport. Bed level gradient and sediment transport were greater on the intermediate beach than on the dissipative beach (case 7), and there is tendency for flattening of the berm and bar on the dissipative beach slope. Roelvink et al. [46] postulated that the behaviour of breaker bars strongly depends on the wave-breaking process and the effect of bottom slope on sand transport. Depth-averaged TKE and volume of sediment that is transported against TKE for all cases are given in panel $\mathrm{b}$. There is a strong correlation between TKE and nearshore deposition/erosion (turbulence contributes to the beach profile changes). The main sources of TKE in the surf and swash zones are breaking waves and bottom shear stress [12]. Generally, the magnitude of TKE in the inner surf zone and in the vicinity of wave breaking is higher than in the swash zone. In the swash zone, due to depth reduction, the TKE appears near the bed. The high bottom shear stress in the swash zone causes highly turbulent motion close to the bed, which would induce high sediment transport in a layer close to the bed.

Figure 13 shows maximum water depth and maximum TKE plotted against wave height, bed slope, wave period and surf scaling parameter. Panels a-c show that, with increasing wave energy and wave power (which include wave height and wave period), and bed slope; the 
maximum flow depth increases. TKE has the same trend as flow depth, except for panel c, in which TKE decreases with increasing wave period. This is due to the fact that for increasing wave period, the breaker type goes from plunging to collapsing, and therefore the TKE decreases. The largest maximum TKE and flow depth were obtained for the largest wave height (case 3). Panel d shows that the minimum TKE occurs for $\varsigma<0.5$, which represents the spilling breaker and dissipative beach. The maximum TKE occurs for case 3, corresponding to the largest wave height, while minimum TKE takes place for the mildest slope. In addition, panel $\mathrm{d}$ shows that the relationship between the flow depth/TKE and surf scaling parameter is nonlinear. This occurs since wave shoaling, breaking and uprush are not essentially related to the surf scaling parameter. In panel $d, \varsigma$ ranges $0.45 \sim 0.62$ for different slopes (cases 6,7 ), 0.65 1 for different wave heights (cases 1-3), and 1 1.31 for different wave periods (cases 4,5). In cases 6 and 7, a decrease in bed slope causes a transition from intermediate-type to dissipative-type beach, as shown by the decrease of $\varsigma$. Therefore, both TKE and water depth decrease as expected. On the contrary, $\varsigma$ decreases from 0.93 to 0.66 (by increasing wave height), implying that waves break in a more plunging manner, therefore TKE and depth increase. In cases 4 and 5, the increase of wave period causes a decrease of TKE and water depth, as shown by the increase of $\varsigma$ from 0.93 to 1.31 . If bed slope and wave height are held constant and the wave period is increased, the breaker type goes from plunging to collapsing to surging [48], therefore, by increasing the wave period, TKE decreases.

Total, onshore, and offshore sediment volume for all cases are given in panel a of Fig. 14. The results show that the milder bottom slope reduces sediment transport. Increased wave energy (height) increases on-offshore sediment transport, while the transport of smaller particles is higher than that of larger particles. In order to obtain the relation between on- and off-shore sediment transport in the nearshore area, panel b shows the onshore sediment transport (above the SWL, [47]) plotted against offshore (below the SWL) sediment transport. 
A linear relationship exists between the two cases with a correlation coefficient 0.77 . Wave energy and wave power can be used to identify the dominant mechanism of sediment transport in the surf and swash zones. Panels c and d show total, onshore and offshore sediment transport plotted against wave energy and wave energy flux for all the cases considered above. A weak linear relationship exists between the offshore sediment transport and wave energy and energy flux (correlation coefficient 0.54 and 0.63 , respectively), while a strong relationships between the onshore sediment transport, and wave energy and energy flux exist (correlation coefficient 0.90 and 0.94 , respectively). The correlation coefficients between total sediment transport, and wave energy and wave energy flux are 0.67 and 0.76 , respectively. Generally, considering present cases, the correlation between sediment transport and wave energy flux is higher than sediment transport and wave energy. This is because in wave energy flux, in addition to wave height, the wave period is taken into account. We augmented the wave power by the beach slope, to obtain $\chi$, as follows:

$\chi=E_{f} \tan ^{1 / 2}(\theta)=\frac{\rho g^{2}}{64 \pi} H^{2} T \tan ^{1 / 2}(\theta)$

Panel e shows total, onshore and offshore sediment transport plotted against $\chi$. The correlation coefficients between sediment volume and $\chi(0.70,0.82$ and 0.96 for offshore, onshore and total sediment transport, respectively) is higher than correlation coefficients between sediment volume, and wave energy and wave energy flux. These results suggest that the $\chi$ is superior to the existing parameters to characterise the hydro- and morphodynamics of the nearshore zone.

\section{Conclusions}

A two-phase flow model for the analysis of nearshore processes (wave and sediment motions in the surf and swash areas) for dissipative and intermediate beaches was presented as a follow up to [13]. The model results are consistent with existing understanding of two-phase 
nearshore flow in terms of water depth, sediment transport and beach morphology, and TKE for different beach types and waves $[4,8,9,11]$. The simulations demonstrate that for intermediate beaches relative to dissipative beaches (i) there is an increase in the TKE and mixing, (ii) water depth is higher and wave-breaking position is changed, depending on wave characteristics, and (iii) foreshore profile change and bar size are greater, and beach slope is steeper. In addition, sediment transport behaviour is erosive (offshore) on the fine sand beach, while sediment transport behaviour is accretionary (onshore) on the coarse sand beach. Larger wave heights and steeper bottom slopes result in higher sediment transport fluxes and beach profile changes. High levels of TKE are correlated with high sediment transport in the nearshore zone. Our results confirm that wave energy, bed slope and sediment grain size are most critical variables to beach profile prediction. We proposed a new parameter that can help characterize sediment transport in the surf and swash zones.

Results of the model show its capability in simulating the foreshore profile changes in the nearshore zone under different wave and beach conditions. Numerical modelling in order to evaluate further this model to simulate collections of mixed sediments having different density and size, and a direct comparison with experiments and/or more complete simulations is needed.

\section{Acknowledgments}

Support of the Swiss National Foundation (SNF 200021-135322) is acknowledged. This manuscript is the extension of authors' paper that was presented at THESIS-2011 conference. Kees acknowledges support from the Internal Research Investment Program of the Coastal and Hydraulics Laboratory. Permission was granted by the Chief of Engineers to publish this information. 


\section{References}

[1] Elfrink B, Baldock TE. Hydrodynamics and sediment transport in the swash zone: A review and perspectives. Coast Eng 2002;45:149-67.

[2] Bakhtyar R, Barry DA, Li L, Jeng D-S, Yeganeh-Bakhtiary A. Modeling sediment transport in the swash zone: A review. Ocean Eng 2009;36:767-83.

[3] Moreno IM, Ávila A, Losada MÁ. Morphodynamics of intermittent coastal lagoons in Southern Spain: Zahara de los Atunes. Geomorphology 2010;121:305-16.

[4] Bakhtyar R, Ghaheri A, Yeganeh-Bakhtiary A, Barry DA. Process-based model for nearshore hydrodynamics, sediment transport and morphological evolution in the surf and swash zones. Appl Ocean Res 2009;31:44-56.

[5] Karunarathna H, Chadwick A, Lawrence J. Numerical experiments of swash oscillations on steep and gentle beaches. Coast Eng 2005;52:497-511.

[6] Alsina JM, Falchetti S, Baldock TE. Measurements and modelling of the advection of suspended sediment in the swash zone by solitary waves. Coast Eng 2009;56:621-31.

[7] Berni C, Michallet H, Barthélemy E. Local processes of bed destabilization in the surf zone. J Coast Res 2011;SI 64:2017-21.

[8] Aagaard T, Hughes MG. Sediment suspension and turbulence in the swash zone of dissipative beaches. Mar Geol 2006;228:117-35.

[9] Masselink G, Evans D, Hughes MG, Russell P. Suspended sediment transport in the swash zone of a dissipative beach. Mar Geol 2005;216:169-89. 
[10] Razmi AM, Bakhtyar R, Barry DA. Numerical simulation of two-phase flow for nearshore hydrodynamics under wave-current interactions. J Coast Res 2011;SI64:11659.

[11] Miles J, Butt T, Russell P. Swash zone sediment dynamics: A comparison of a dissipative and an intermediate beach. Mar Geol 2006;231:181-200.

[12] Bakhtyar R, Barry DA, Yeganeh-Bakhtiary A, Ghaheri A. Numerical simulation of surfswash zone motions and turbulent flow. Adv Water Resour 2009;32:250-63.

[13] Bakhtyar R, Barry DA, Yeganeh-Bakhtiary A, Li L, Parlange J-Y, Sander GC. Numerical simulation of two-phase flow for sediment transport in the inner-surf and swash zones. Adv Water Resour 2010;33:277-90.

[14] Van Rijn LC. Principles of sediment transport in rivers, estuaries and coastal seas. Aqua Publications 1993, The Netherlands.

[15] Bakhtyar R, Yeganeh-Bakhtiary A, Barry DA, Ghaheri A. Two-phase hydrodynamic and sediment transport modeling of wave-generated sheet flow. Adv Water Resour 2009;32:1267-83.

[16] Drew DA. Turbulent sediment over a flat bottom using momentum balance. J Appl Mech $1975 ; 97: 38-44$.

[17] Jha SK, Bombardelli FA. Toward two-phase flow modeling of nondilute sediment transport in open channels. J Geophys Res 2010;115:F03015, doi:10.1029/2009JF001347.

[18] Jha SK, Bombardelli FA. Two-phase modeling of turbulence in dilute sediment-laden, open-channel flows. Environ Fluid Mech 2009;9:237-66. 
[19] Toorman EA. Vertical mixing in the fully developed turbulent layer of sediment-laden open-channel flow. J Hydraul Eng 2008;134:1225-35.

[20] Greimann BP, Holly FM. Two-phase analysis of concentration profiles. J Hydraul Eng 2001;127: 753-62.

[21] Loth E. Numerical approaches to dilute two-phase flow. Prog Energy Combust Sci 2000;26:161-223.

[22] Balachandar S, Eaton JK. Turbulent dispersed multiphase flow. Ann Rev Fluid Mech 2010;42:111-33.

[23] Nguyen KD, Guillou S, Chauchat J. Barbry N. A two-phase numerical model for suspended-sediment transport in estuaries. Adv Water Resour 2009;32:1187-96.

[24] Hsu T, Chang H, Hsieh C. A two-phase flow model of wave-induced sheet flow. J Hydraul Res 2003;41:299-310.

[25] Hsu T-J, Jenkins JT, Liu PL-F. On two-phase sediment transport: Sheet flow of massive particles. Proc Roy Soc London Ser A 2004;460:2223-50.

[26] Hsu T-J, Hanes DM. Effects of wave shape on sheet flow sediment transport. J Geophys Res 2004;109: C05025, doi: 10.1029/2003JC002075.

[27] Asano T. Two-phase flow model on oscillatory sheet flow. In: Proceedings of 22nd international conference on coastal engineering, ASCE; 1990. p. 2372-84.

[28] Kobayashi N, Seo SN. Fluid and sediment interaction over a plane bed. J Hydraul Eng $1985 ; 111: 903-21$. 
[29] Dong P, Zhang K. Two-phase flow modeling of sediment motions in oscillatory sheet flow. Coast Eng 1999;36:87-109.

[30] Liu H, Sato S. Modeling sediment movement under sheet flow conditions using a twophase flow approach. Coast Eng Jpn 2005;47:255-84.

[31] Liu H, Sato S. A two-phase flow model for asymmetric sheet flow conditions. Coast Eng 2006;53:825-43.

[32] Bakhtyar R, Yeganeh-Bakhtiary A, Barry DA, Ghaheri A. Euler-Euler coupled twophase flow modeling of sheet flow sediment motion in the nearshore. J Coast Res 2009;SI56:467-71.

[33] Elghobashi SE, Abou-Arab TW. A two-equation turbulence model for two-phase flows. Phys Fluids 1983;26:931-8.

[34] Bagnold RA. Experiments on a gravity-free dispersion of large solid spheres in a Newtonian fluid under shear. Proc Roy Soc London Ser A 1954;225:49-63.

[35] Ting FCK. Laboratory study of wave and turbulence characteristics in narrow-band irregular breaking waves. Coast Eng 2002;46:291-313.

[36] Iribarren CR, Nogales C. Protection des ports. In: Section II, communication 4, XVII ${ }^{\text {th }}$ international naval congress, Lisbon, Portugal; 1949. p. 31-80.

[37] Guza RT, Inman DL. Edge waves and beach cusps. J Geophys Res 1975;80:2997-3012.

[38] Phillips OM. The dynamics of the upper ocean. 1977, $2^{\text {nd }}$ ed. Cambridge University Press. 
[39] Wave Energy Potential on the U.S. Outer Continental Shelf. Minerals Management Service, Renewable Energy and Alternate Use Program, United States Department of the Interior, 2006, http://ocsenergy.anl.gov, last accessed 25 March 2012.

[40] Zheng YH, Shen YM, Wu XG, You YG. Determination of wave energy dissipation factor and numerical simulation of wave height in the surf zone. Ocean Eng 2004;31:1083-92.

[41] Bakhtyar R, Razmi AM, Barry DA, Yeganeh-Bakhtiary A, Zou Q-P. Air-water two-phase flow model of turbulent surf and swash zone wave motions. Adv Water Resour 2010;33:1560-74.

[42] Horn DP, Baldock TE, Li L. The influence of groundwater on profile evolution of fine and coarse sand beaches. Proceedings of Coastal Sediments '07, New Orleans, ASCE, 2007, pp. 506-19.

[43] Bakhtyar, R., Barry DA, Brovelli A. Numerical experiments on interactions between wave motion and variable-density coastal aquifers. Coast Eng 2011;60:95-108.

[44] Turner IL, Masselink G. Swash infiltration-exfiltration and sediment transport. J Geophys Res 1998;103:30813-25.

[45] Bakhtyar R, Brovelli A, Barry DA, Li L. Wave-induced watertable fluctuations, sediment transport and beach profile change: Modeling and comparison with large-scale laboratory experiments. Coast Eng 2011;58:103-18.

[46] Roelvink JA, Reniers AJHM. LIP11 D Delta flume experiment: A dataset for profile validation. Report H2130, 1995, Delft Hydraulics, Delft, The Netherlands, www.wldelft.nl, last accessed 25 March 2012. 
[47] Schwartz ML. Encyclopedia of coastal science. 2005. Springer, Dordrecht, The Netherlands.

[48] Galvin Jr CJ. Wave breaking in shallow water. In: Meyer RE, editor. Waves on beaches and resulting sediment transport. New York: Academic Press; 1972. p. 413-56. 
Table 1. Characteristics of the waves and beach conditions in the numerical experiments.

\begin{tabular}{|c|c|c|c|c|c|c|c|}
\hline Case & $H(\mathrm{~m})$ & $D_{50}(\mathrm{~mm})$ & $T(\mathrm{~s})$ & $\theta$ & $\xi$ & $\varsigma$ & Beach type \\
\hline 1 & 0.10 & 0.5 & 2.4 & $1: 10$ & 6.98 & 0.93 & intermediate \\
\hline 2 & 0.15 & 0.5 & 2.4 & $1: 10$ & 10.52 & 0.76 & intermediate \\
\hline 3 & 0.20 & 0.5 & 2.4 & $1: 10$ & 17.50 & 0.66 & intermediate \\
\hline 4 & 0.10 & 0.5 & 3 & $1: 10$ & 4.46 & 1.16 & intermediate \\
\hline 5 & 0.10 & 0.5 & 3.4 & $1: 10$ & 3.46 & 1.31 & intermediate \\
\hline 6 & 0.10 & 0.5 & 2.4 & $1: 15$ & 15.30 & 0.62 & intermediate \\
\hline 7 & 0.10 & 0.5 & 2.4 & $1: 20$ & 27.94 & 0.46 & dissipative \\
\hline 8 & 0.10 & 0.15 & 2.4 & $1: 10$ & 6.98 & 0.93 & intermediate \\
\hline 9 & 0.10 & 0.35 & 2.4 & $1: 10$ & 6.98 & 0.93 & intermediate \\
\hline 10 & 0.10 & 0.85 & 2.4 & $1: 10$ & 6.98 & 0.93 & intermediate \\
\hline
\end{tabular}




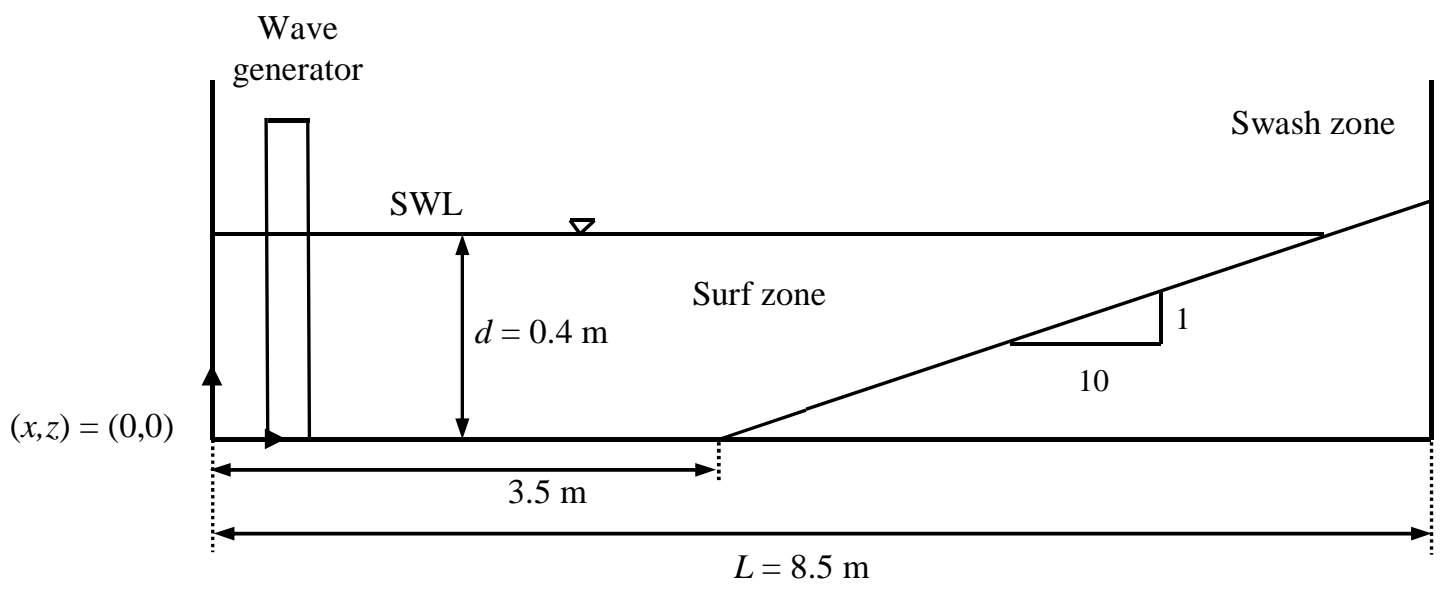

Figure 1. Sketch of model setup (after [13]). 


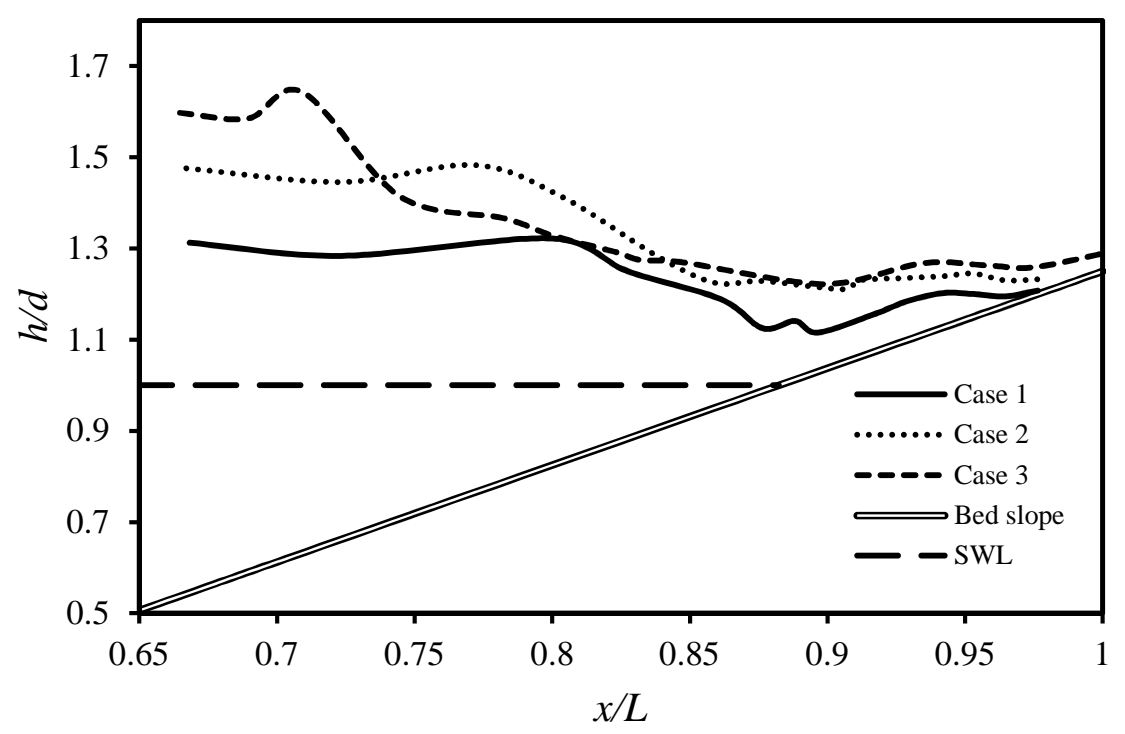

Figure 2. Cross-shore variation of water depth in the nearshore for different wave heights $(H / d$ $=0.25$, case $1 ; H / d=0.375$, case $2 ;$ and $H / d=0.50$, case 3 ; for all cases $T=2.4 \mathrm{~s}$ and $\theta=$ 1:10). 


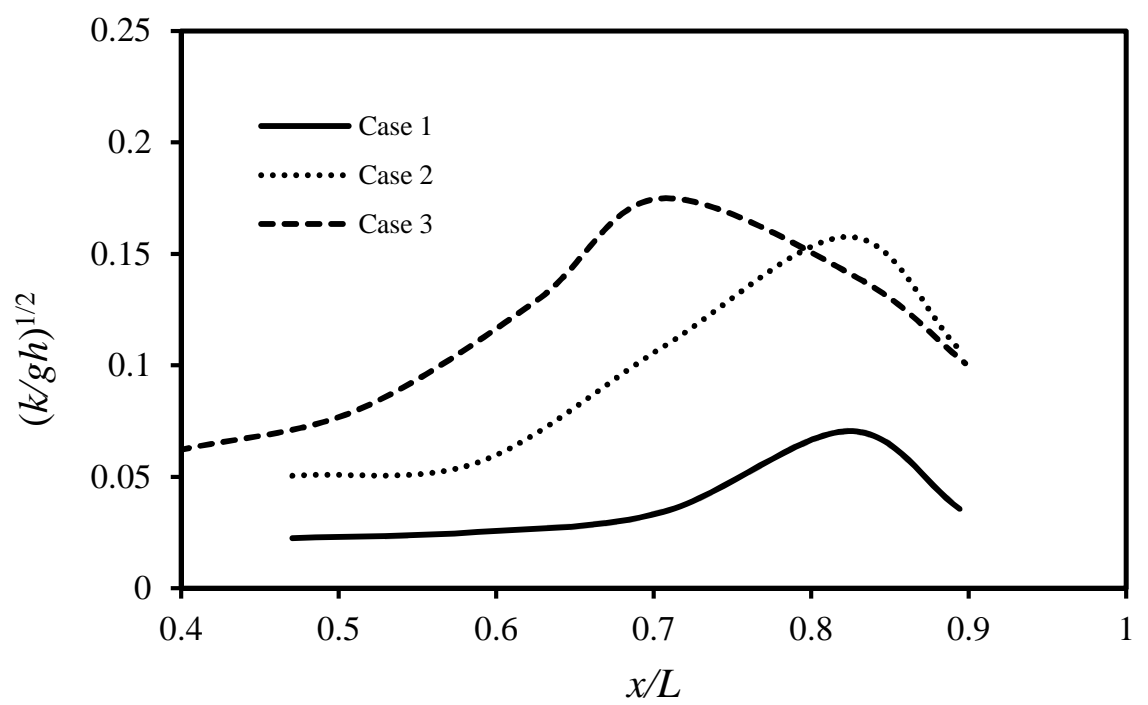

Figure 3. Spatial distributions of turbulent kinetic energy (TKE) in the cross-shore direction for different wave heights $(H / d=0.25$, case $1 ; H / d=0.375$, case 2 ; and $H / d=0.50$, case 3 ; for all cases $T=2.4 \mathrm{~s}$ and $\theta=1: 10$ ). 


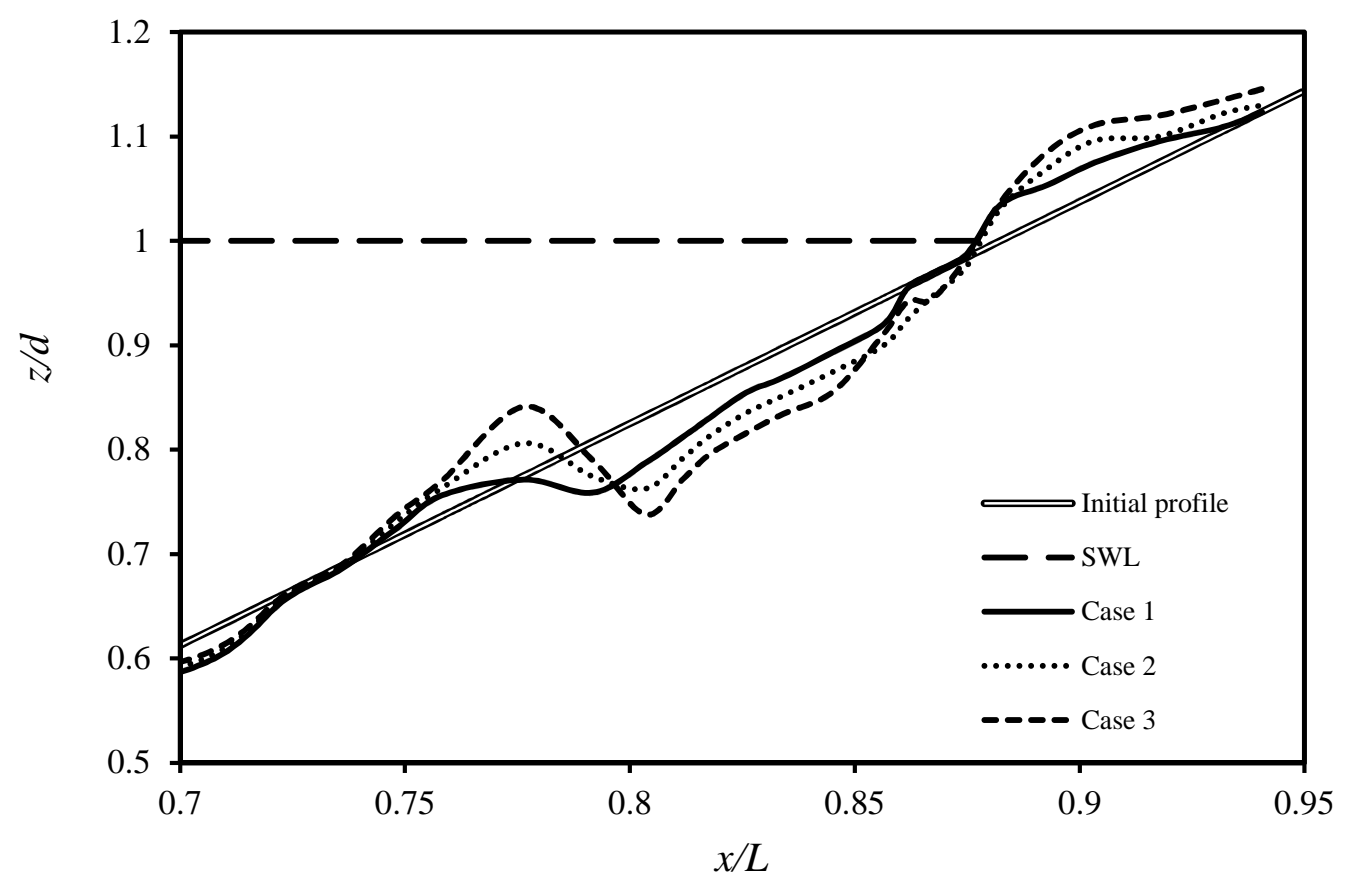

Figure 4. Numerical results for beach face profile changes for different wave heights $(H / d=$ 0.25 , case $1 ; H / d=0.375$, case 2 ; and $H / d=0.50$, case 3 ; for all cases $T=2.4 \mathrm{~s}$ and $\theta=1: 10$ ). 


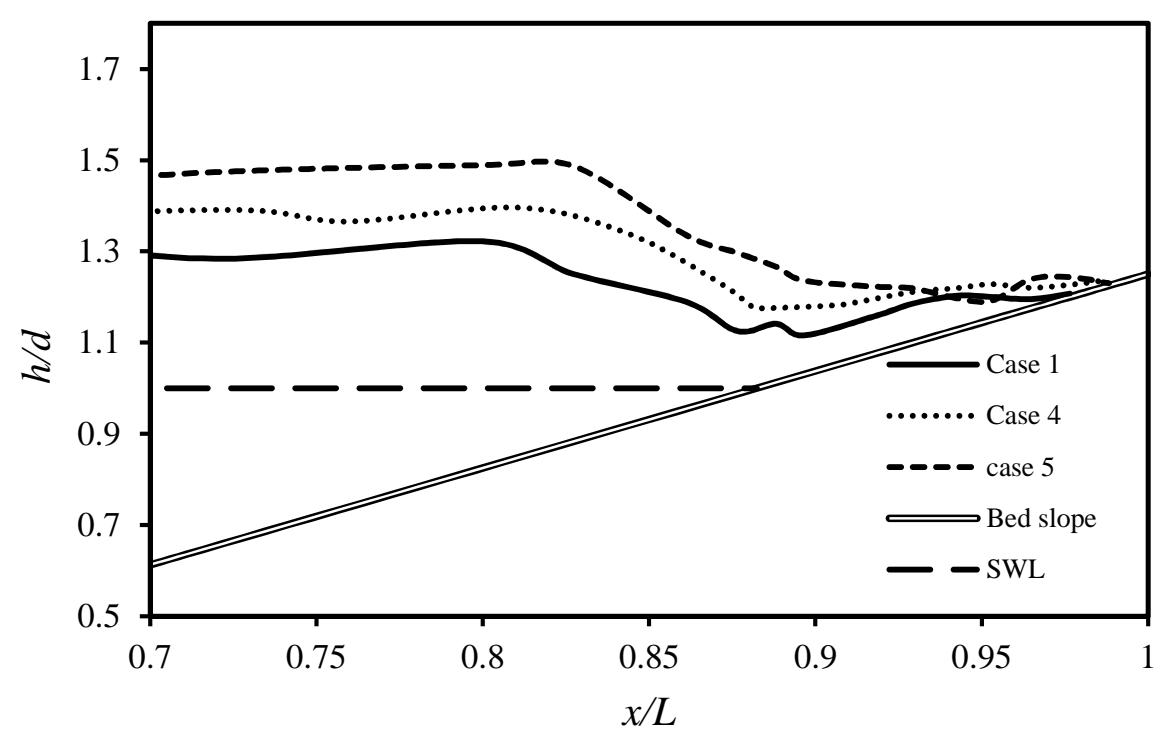

Figure 5. Cross-shore variation of water depth in the nearshore for different wave periods $(T=$ $2.4 \mathrm{~s}$, case $1 ; T=3 \mathrm{~s}$, case 4 ; and $T=3.4 \mathrm{~s}$, case 5 ; for all cases $H / d=0.25$ and $\theta=1: 10$ ). 


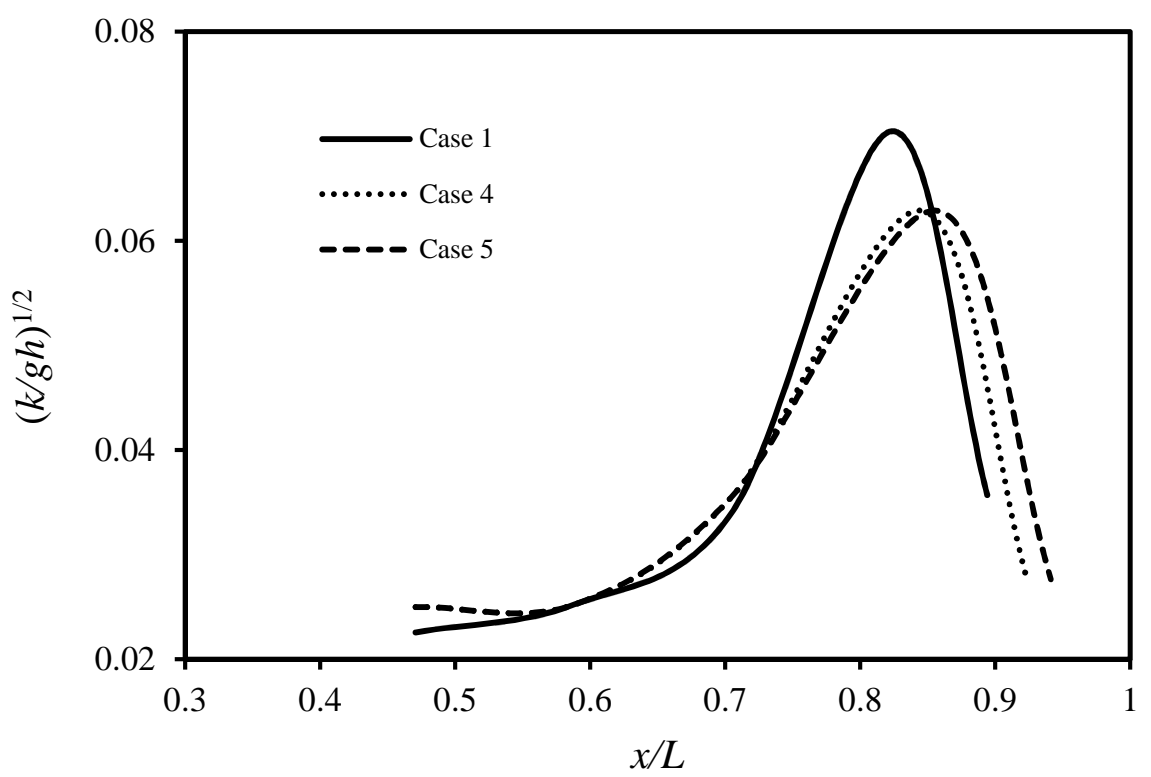

Figure 6. Spatial distributions of turbulent kinetic energy (TKE) in the cross-shore direction for different wave periods $(T=2.4 \mathrm{~s}$, case $1 ; T=3 \mathrm{~s}$, case 4 ; and $T=3.4 \mathrm{~s}$, case 5 ; for all cases $H / d=0.25$ and $\theta=1: 10)$. 


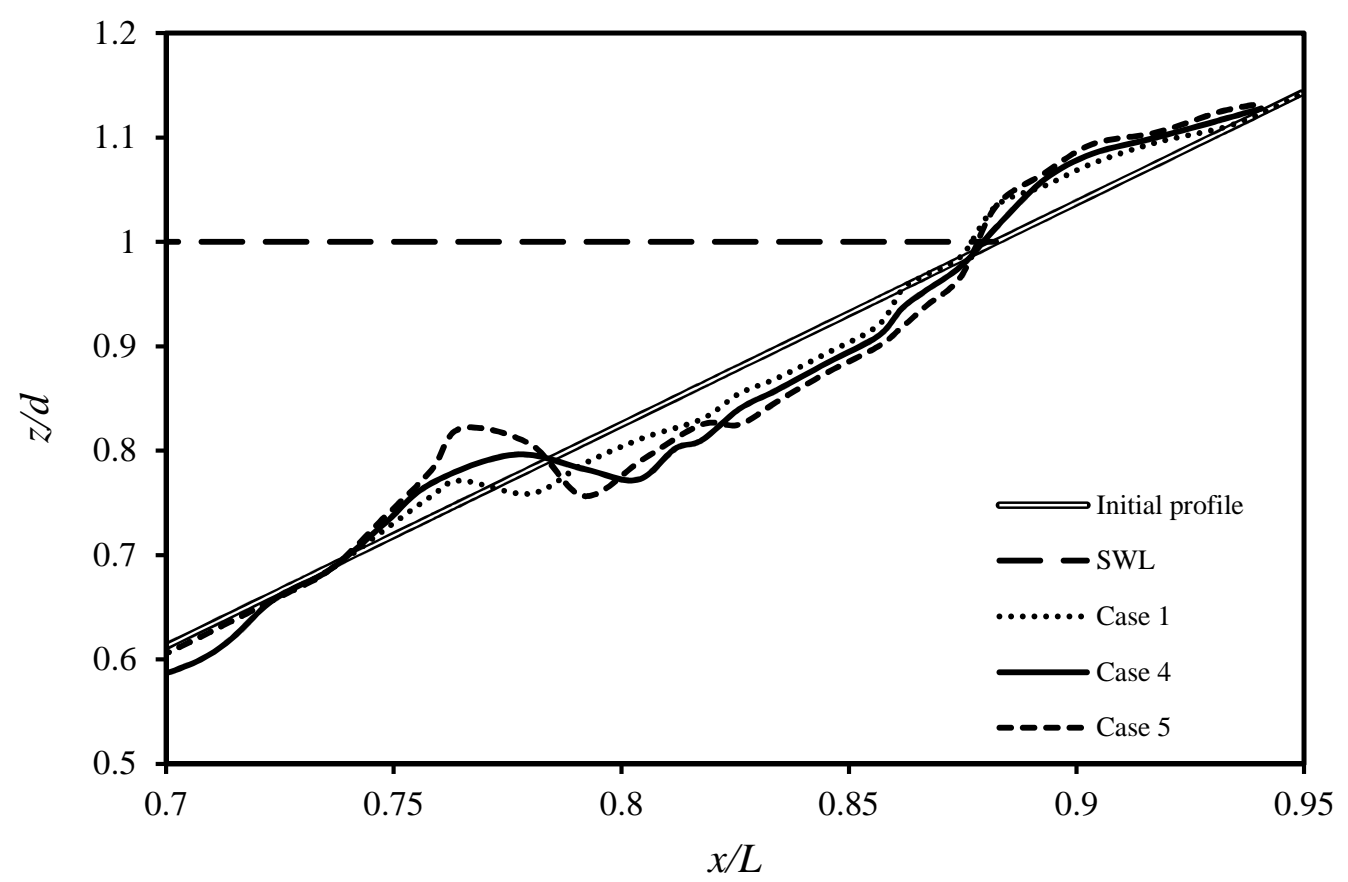

Figure 7. Numerical results for beach face profile changes for different wave periods $(T=2.4$ s, case $1 ; T=3 \mathrm{~s}$, case 4 ; and $T=3.4 \mathrm{~s}$, case 5 ; for all cases $H / d=0.25$ and $\theta=1: 10$ ). 


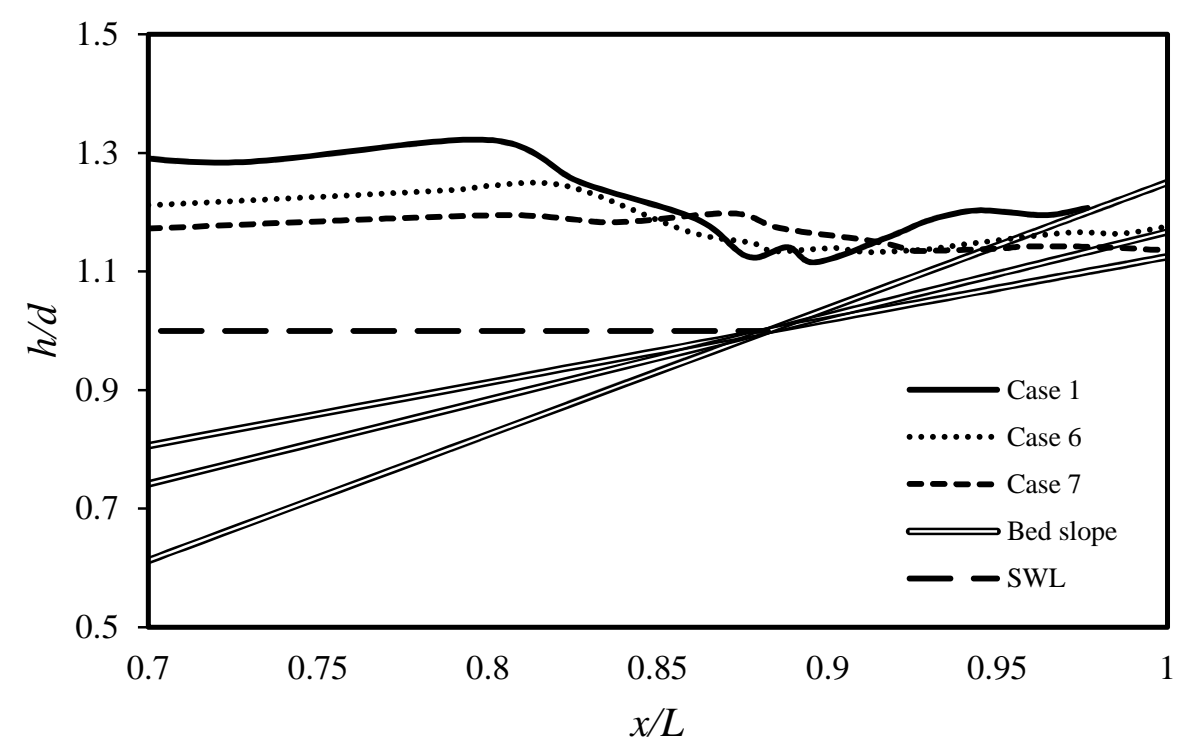

Figure 8. Cross-shore variation of water depth in the nearshore for different bottom slopes ( $\theta$ $=1: 10$, case $1 ; \mathrm{s} \theta=1: 15$, case 6 ; and $\theta=1: 20$, case 7 ; for all cases $H / d=0.25$ and $T=2.4 \mathrm{~s}$ ). 


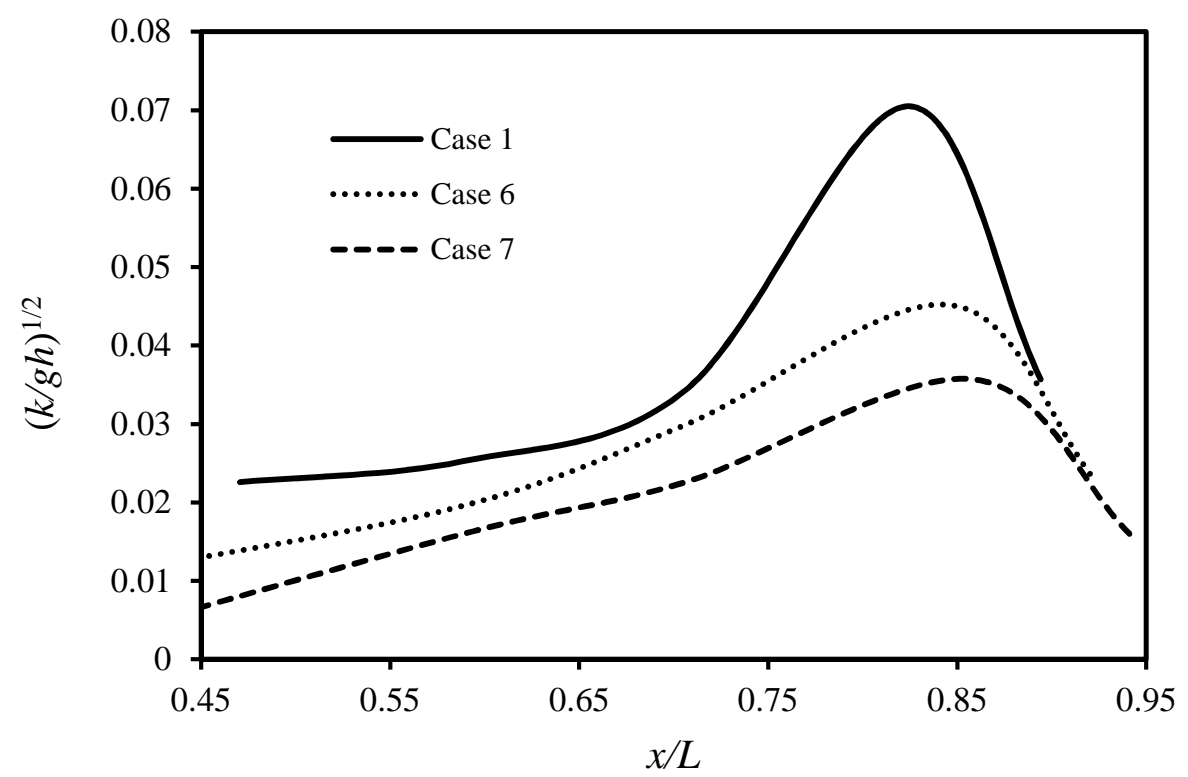

Figure 9. Spatial distributions of turbulent kinetic energy (TKE) in the cross-shore direction for different bottom slopes ( $\theta=1: 10$, case $1 ; \theta=1: 15$, case 6 ; and $\theta=1: 20$, case 7 ; for all cases $H / d=0.25$ and $T=2.4 \mathrm{~s}$ ). 


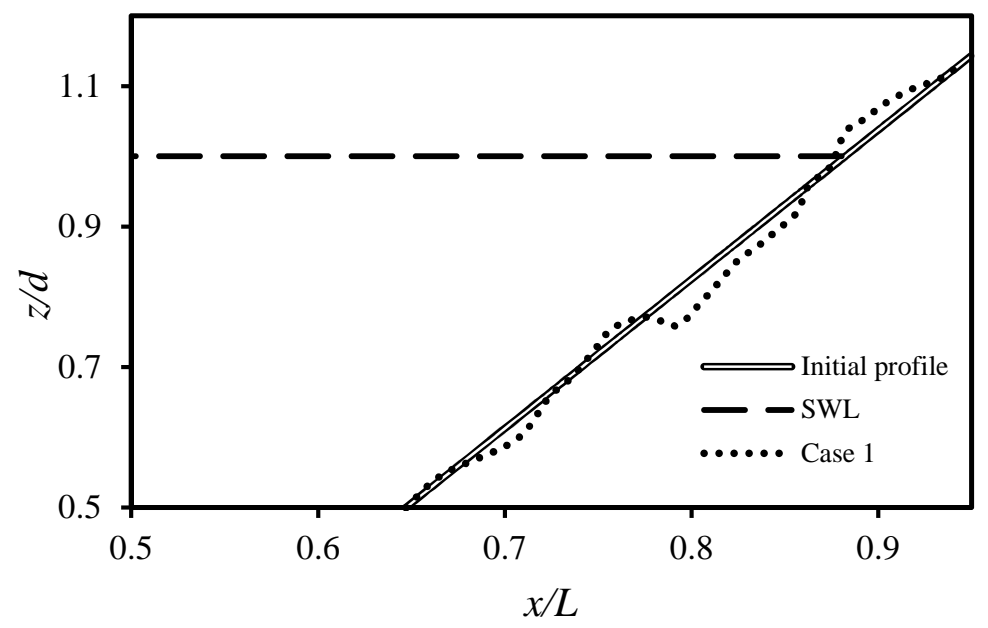

(a)

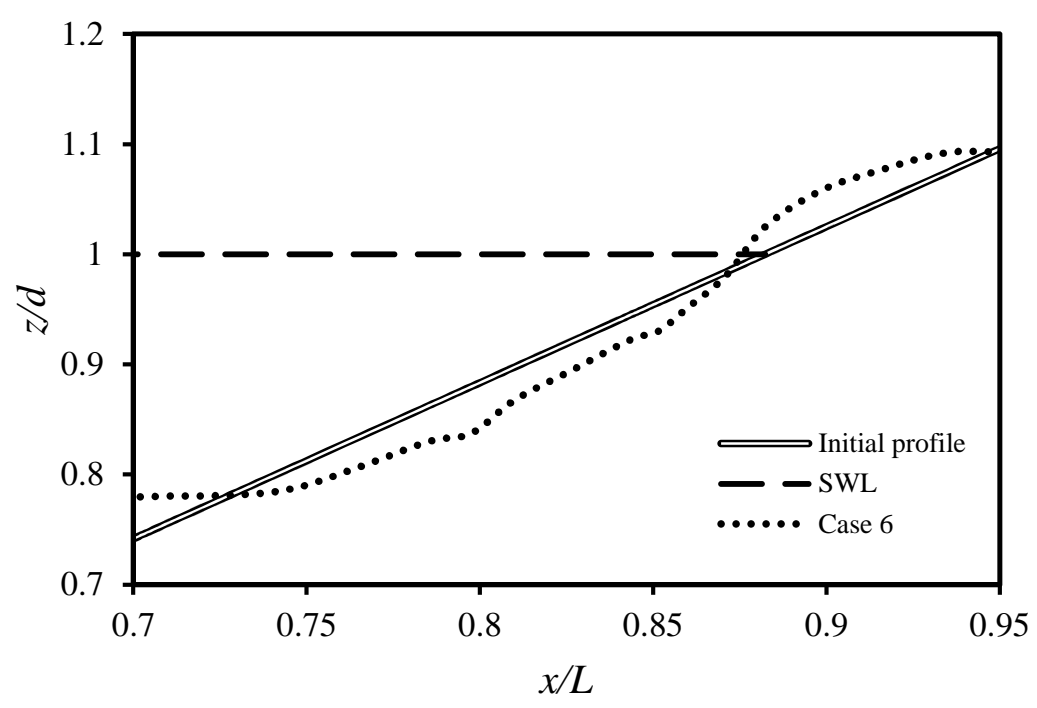

(b)

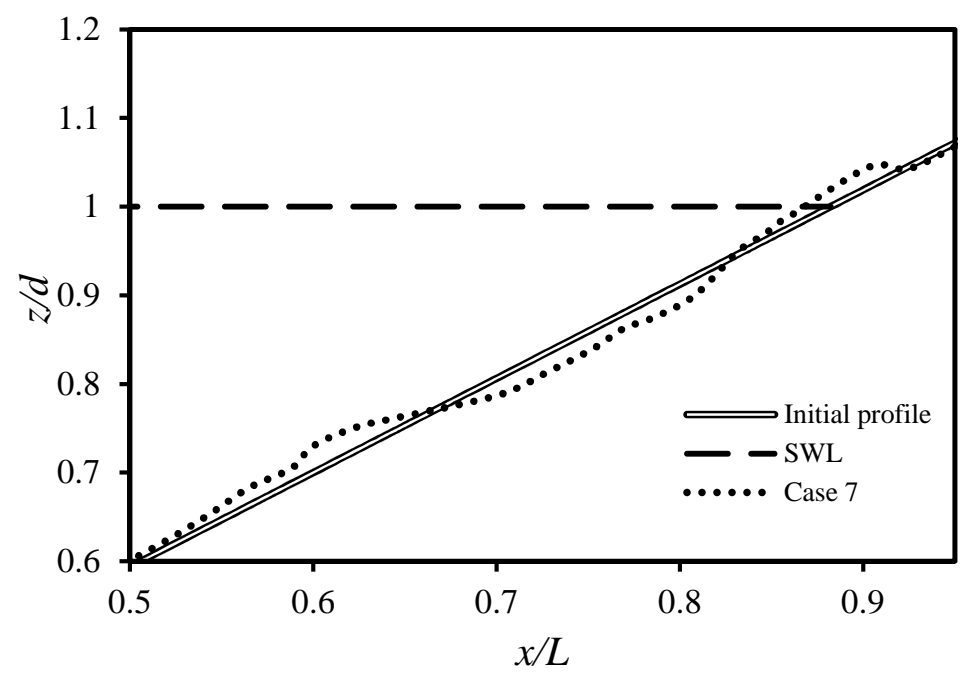


(c)

Figure 10. Numerical results for beach face profile changes for different bottom slopes: (a) $\theta$ $=1: 10$, case 1 ; (b) $\theta=1: 15$, case 6 ; and (c) $\theta=1: 20$, case 7 ; for all cases $H / d=0.25$ and $T=$ $2.4 \mathrm{~s})$. 


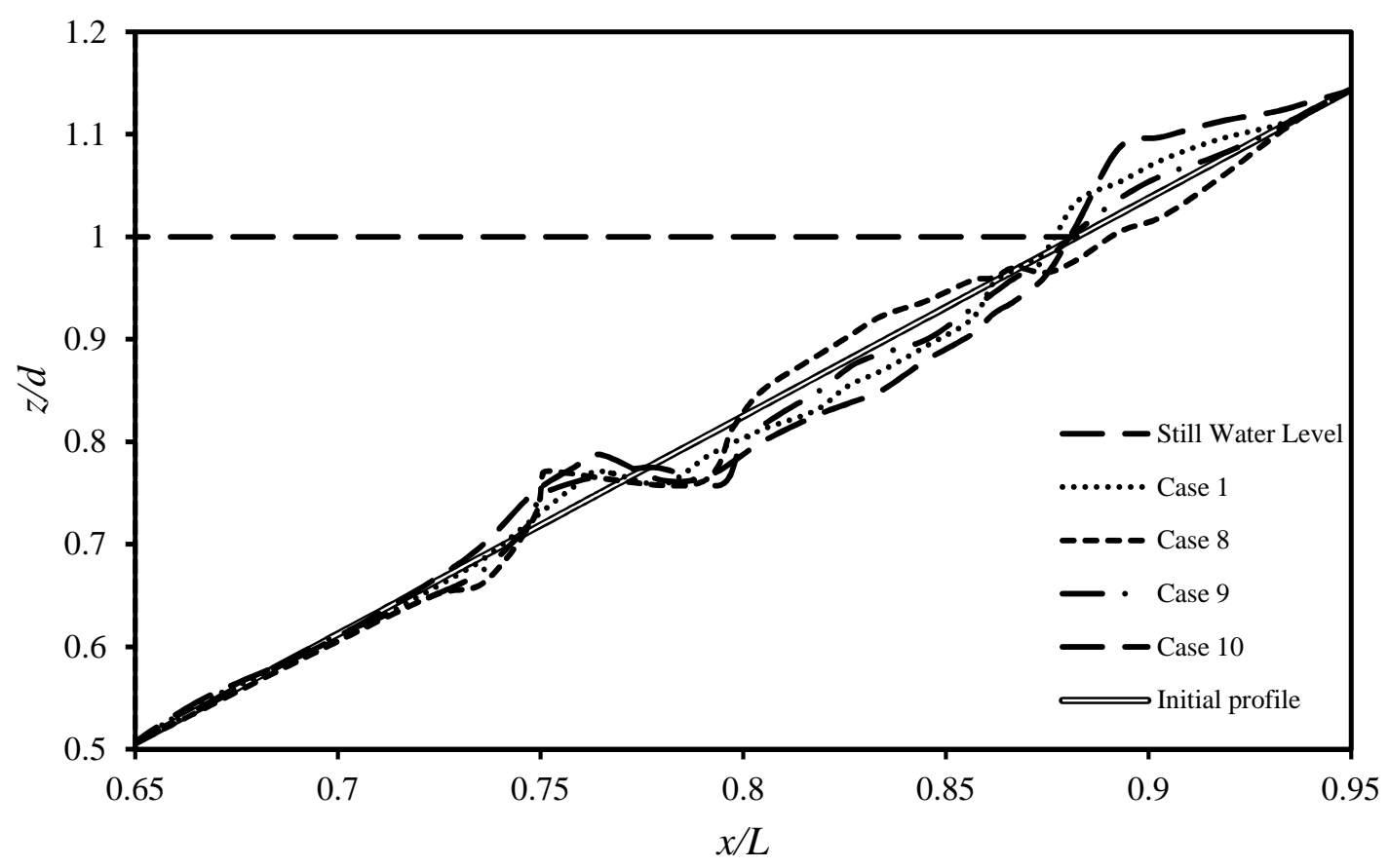

Figure 11. Numerical results for foreshore profile changes on the coarse and fine sand beaches for cases 1 and 8-10. For all curves $H / d=0.25, T=2.4 \mathrm{~s}, \theta=1: 10$. 


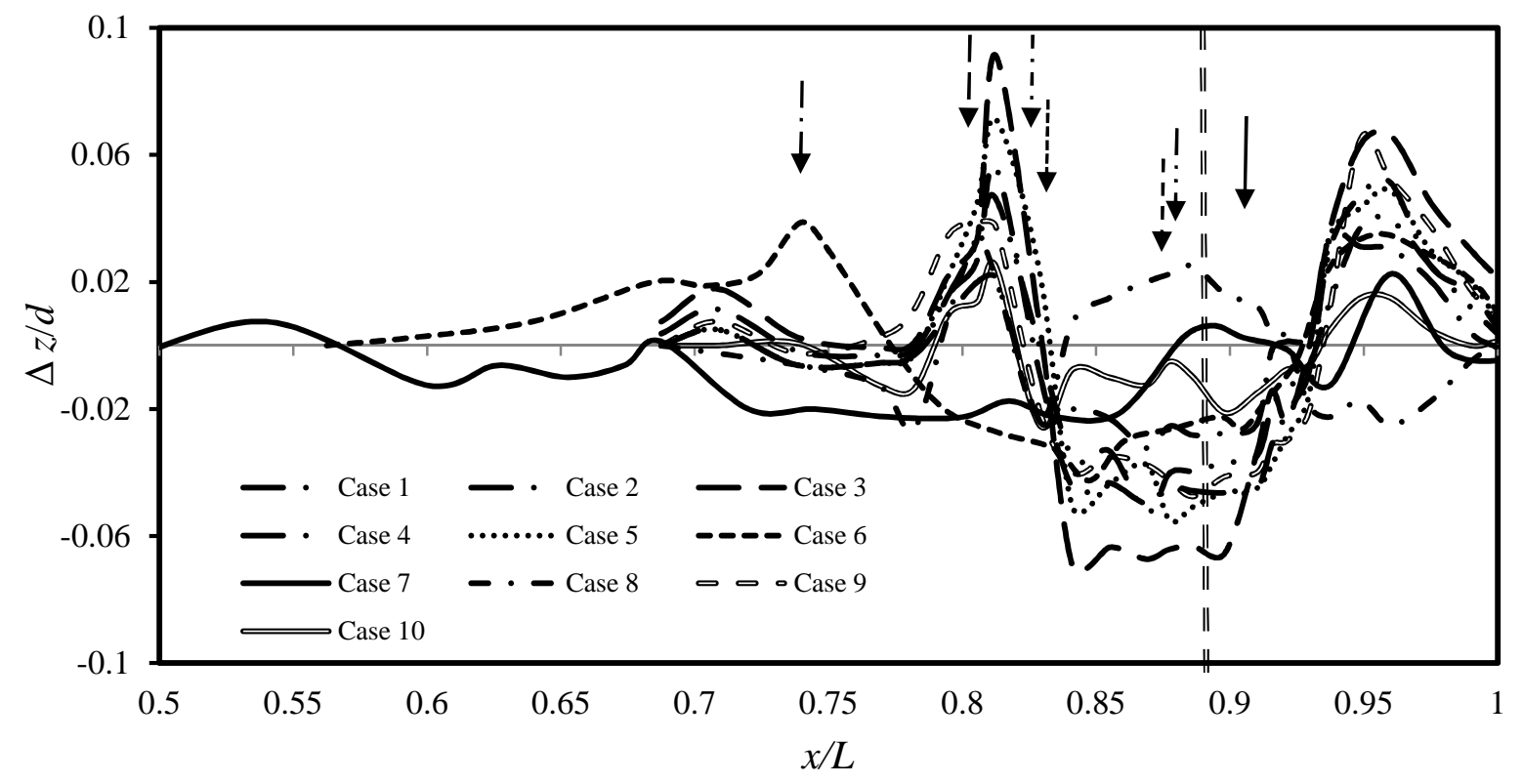

(a)

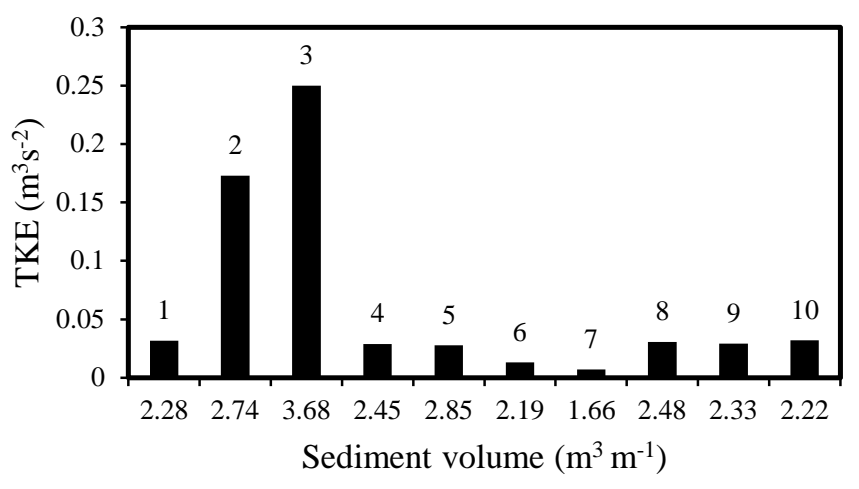

(b)

Figure 12. (a) Simulated bed level changes (where $L$ is the model domain and $d$ is the still water depth; positive and negative values show deposition and erosion, respectively; vertical dash line show location of SWL), and (b) sediment volume vs. TKE for all cases. Vertical arrows in (a) show the position of the wave-breaking points. Numbers above the bars in (b) indicate case numbers. 


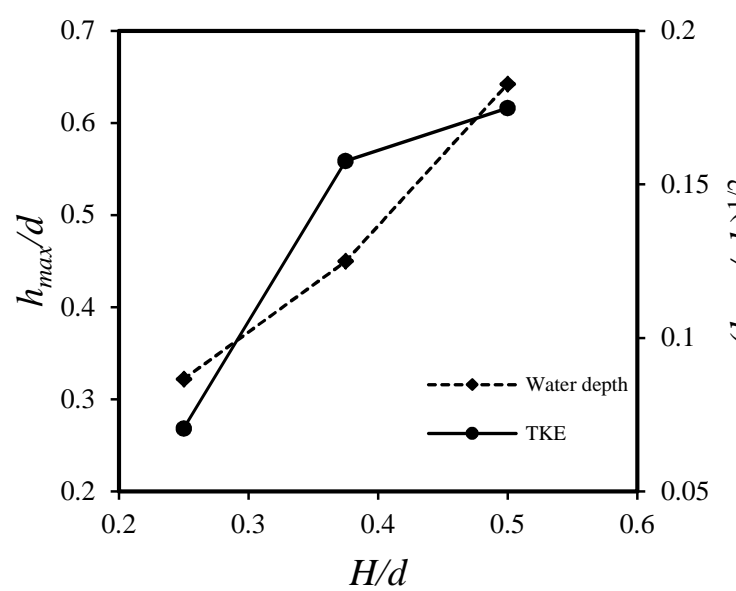

(a)

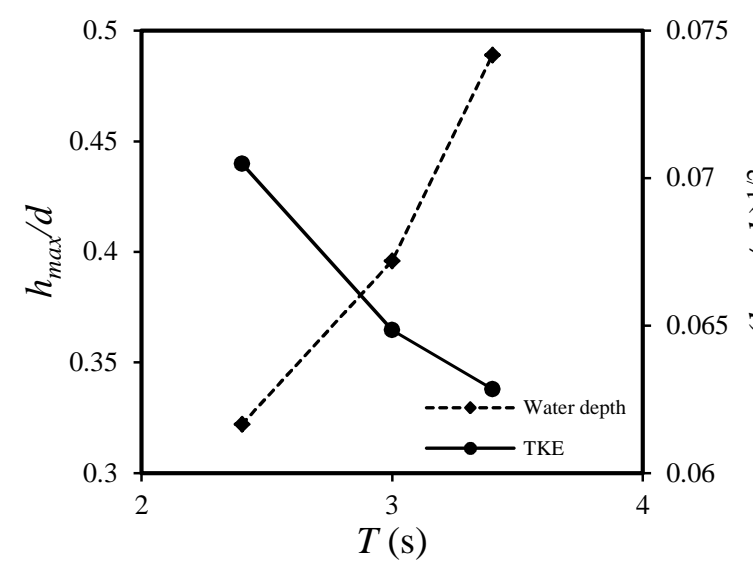

(c)

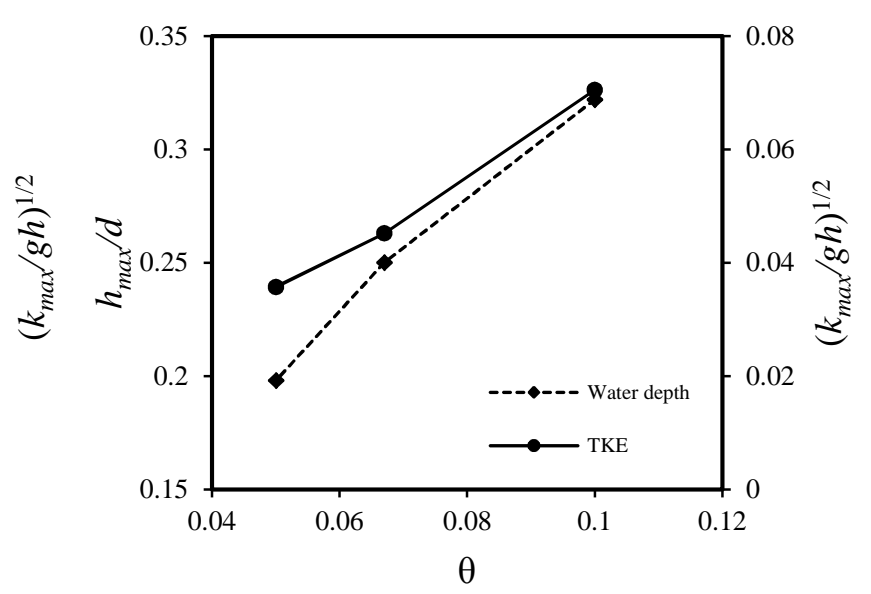

(b)

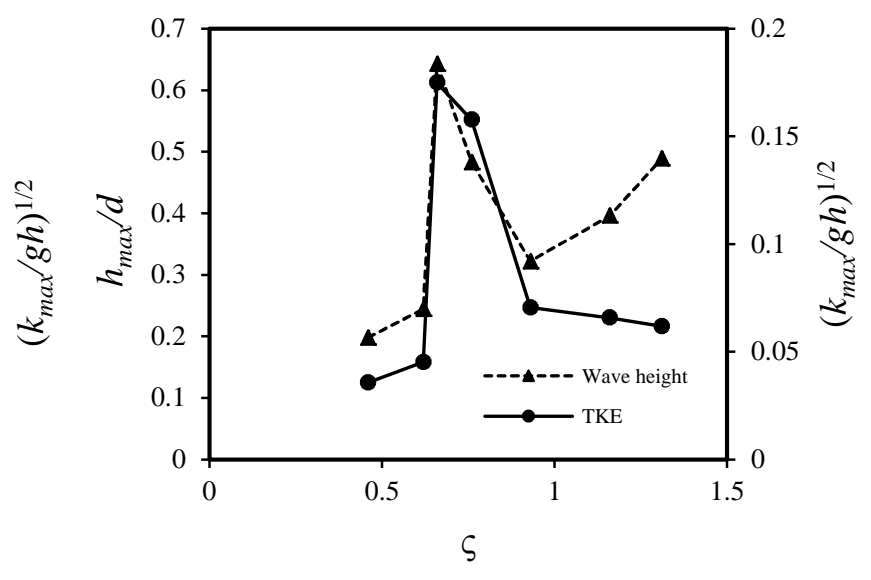

(d)

Figure 13. Non-dimensional maximum water depth and maximum TKE vs. (a) wave height, (b) bed slope, (c) wave period, and (d) surf scaling parameter. 


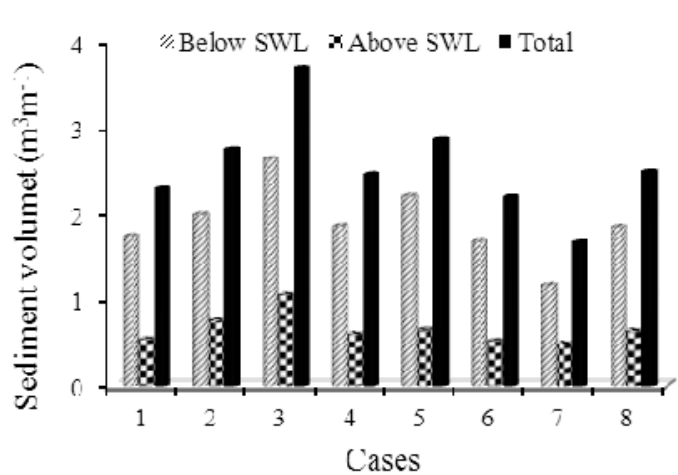

(a)

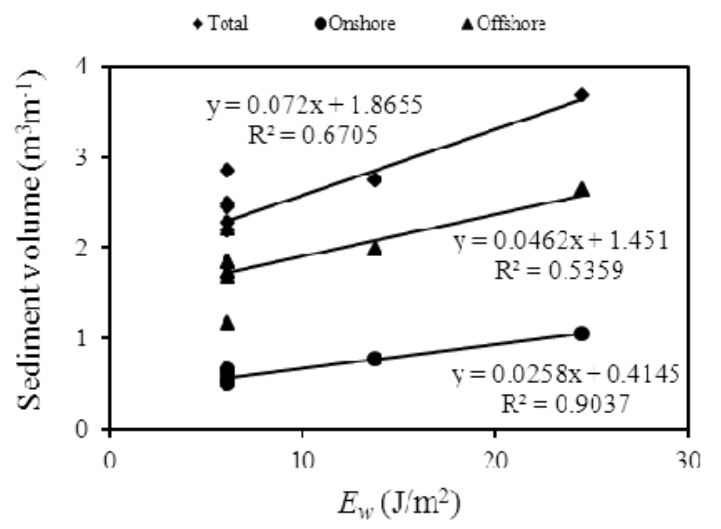

(c)

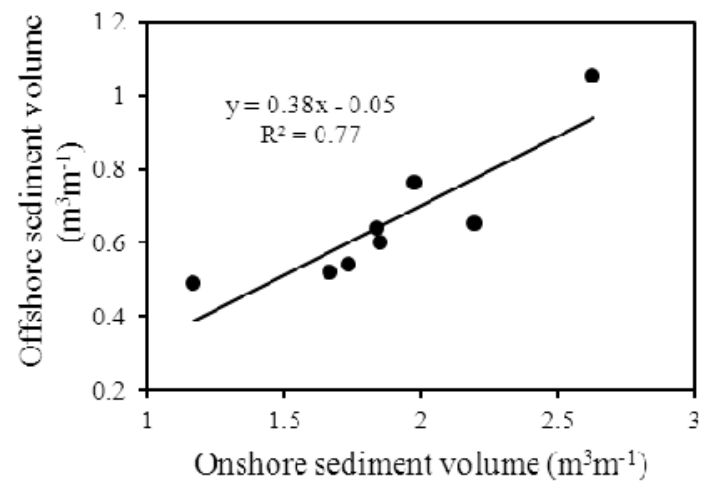

(b)

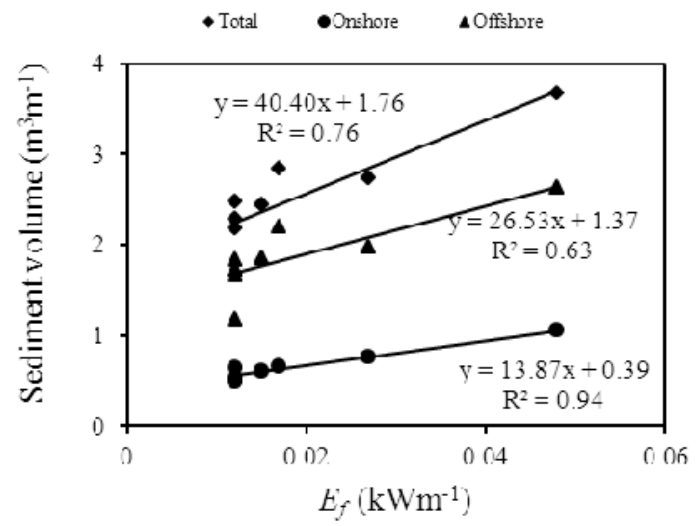

(d)

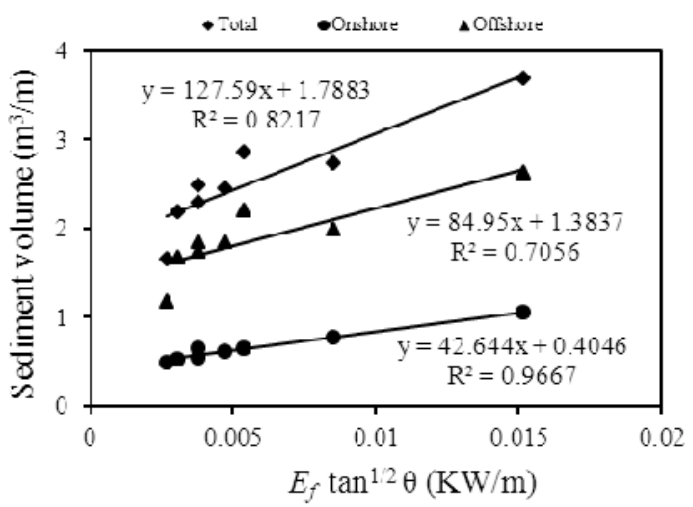

(e)

Figure 14. (a) Total, onshore, and offshore sediment volume, the maximum on-offshore sediment transport occurs for case 3, corresponding to the largest wave height, while the minimum sediment transport takes place for the mildest slope (case 7). (b) Onshore sediment volume vs. offshore sediment volume, (c) sediment volume vs. wave energy, (d) sediment volume vs. wave energy flux, and (e) sediment volume vs. $\chi=E_{f} \tan ^{1 / 2}(\theta)$. 